\title{
Sensitivity Analysis of Biome-BGCMuSo for Gross and Net Primary Productivity of Typical Forests in China
}

\section{Hongge Ren}

Aerospace Information Research Institute, Chinese Academy of Sciences

\section{Li Zhang}

Aerospace Information Research Institute, Chinese Academy of Science

\section{Min Yan ( $\square$ yanmin@aircas.ac.cn )}

Aerospace Information Research Institute, Chinese Academy of Science https://orcid.org/0000-00025068-4215

\section{Xin Tian}

Institute of Forest Resource Information Techniques, Chinese Academy of Forest

\section{Xingbo Zheng}

Key Laboratory of Forest Ecology and Management, Institute of Applied Ecology, Chinese Academy of Sciences

\section{Research}

Keywords: Sensitivity Analysis, Biome-BGCMuSo, productivity, regression analysis, EFAST

Posted Date: August 3rd, 2021

DOI: https://doi.org/10.21203/rs.3.rs-757618/v1

License: (c) (i) This work is licensed under a Creative Commons Attribution 4.0 International License. Read Full License

Version of Record: A version of this preprint was published at Forest Ecosystems on December 1st, 2022. See the published version at https://doi.org/10.1016/j.fecs.2022.100011. 


\title{
Sensitivity Analysis of Biome-BGCMuSo for Gross and
} Net Primary Productivity of Typical Forests in China

\author{
Hongge Ren ${ }^{1,2}$, Li Zhang ${ }^{1}$, Min Yan ${ }^{1, ~}$, Xin Tian ${ }^{3}$, Xingbo Zheng ${ }^{4,5}$
}

1 Aerospace Information Research Institute, Chinese Academy of Sciences, No. 9 Dengzhuang SouthRoad, Beijing 100094, China; renhg@aircas.ac.cn (H.R.); zhangli@aircas.ac.cn(L.Z.); yanmin@aircas.ac.cn (M.Y.)

2 University of Chinese Academy of Sciences, Beijing 100049, China

3 Institute of Forest Resource Information Techniques, Chinese Academy of Forestry, Yiheyuanhou, 100091, Beijing, P.R. China; tianxin@caf.ac.cn (X.T.)

4 Key Laboratory of Forest Ecology and Management, Institute of Applied Ecology, Chinese Academy of Sciences, Shenyang 110016, China; zhxb@iae.ac.cn (X.Z.)

5 Research Station of Changbai Mountain Forest Ecosystems, Chinese Academy of Sciences, Antu 133613, Jilin, China

* Correspondence: yanmin@aircas.ac.cn; Tel.: +86-010-8217-8193

\section{Abstract}

Background: Process-based models are widely used to simulate forest productivity, but complex parameterization and calibration challenge the application and development of these models. Sensitivity analysis of numerous parameters is an essential step in model calibration and carbon flux simulation. However, parameters are not dependent on each other, and the results of sensitivity analysis usually vary due to different forest types and regions. Hence, global and representative sensitivity analysis would provide reliable information for simple calibration.

Methods: To determine the contributions of input parameters to gross primary productivity (GPP) and net primary productivity (NPP), regression analysis and extended Fourier amplitude sensitivity testing (EFAST) were conducted for Biome-BGCMuSo to calculate the sensitivity index of the parameters at four observation sites under climate gradient from ChinaFLUX.

Results: Generally, GPP and NPP were highly sensitive to C: $\mathrm{N}_{\text {leaf }}$ (C:N of leaves), $\mathrm{W}_{\text {int }}$ (canopy water interception coefficient), $\mathrm{k}$ (canopy light extinction coefficient), FLNR (fraction of leaf N in Rubisco), $\mathrm{MR}_{\text {pern }}$ (maintenance respiration in $\mathrm{kg}$ C/day per $\mathrm{kg}$ of tissue $\mathrm{N}$ ), $\mathrm{VPD}_{\mathrm{f}}$ (vapor pressure deficit complete conductance reduction), and SLA1 (canopy average specific leaf area in phenological phase 1) at all observation sites. Various sensitive parameters occurred at four observation sites within different climate zones. GPP and NPP were particularly sensitive to FLNR, SLA1 and $\mathrm{W}_{\mathrm{int}}$, and C: $\mathrm{N}_{\text {leaf }}$ in temperate, alpine and subtropical zones, respectively.

Conclusions: The results indicated that sensitivity parameters of China's forest ecosystems change with climate gradient. We found that parameter calibration should be performed according to plant functional type (PFT), and more attention needs to be paid to the differences in climate and environment. These findings contribute to determining the target parameters in field experiments and model calibration. 


\section{Introduction}

Forests can remove approximately one quarter of the carbon dioxide emitted by fossil fuels and industry, becoming one of the most important nature-based solutions to climate change (Seidl et al. 2017; FAO 2020; Cook-Patton et al. 2020). Accurate simulation of forest carbon fluxes, for example, gross primary productivity (GPP) and net primary productivity (NPP), is an important element of the terrestrial ecosystem carbon cycle and global climate change research. Process-based simulation (PBS) models (e.g., Biome-BGCMuSo, Community Land Model) take atmosphere-vegetation-soil as a continuous and dynamic system to establish material and energy exchange modules (Pan et al. 2014; Sun et al. 2017) and can describe the main processes of forest ecosystems (e.g., carbon, nitrogen, and water flux dynamics). Recently, the development of PBS models has provided potential opportunities in terms of terrestrial ecosystem carbon and water cycles and their responses to global climate change (Zaehle et al. 2005; Wang et al. 2011; Li et al. 2020). The running of PBS models relies on conventional ground data, including climatology, meteorology, and vegetation ecophysiological parameters, which results in uncertainties in model outputs due to insufficient prior knowledge of site-specific input parameters (Zhou et al. 2021). Therefore, model calibration by identifying the most influential parameters is necessary for the accurate simulation of carbon and water fluxes.

Sensitivity analysis quantifies how changes in model outputs are attributed to variations in input parameters, and it is widely used in uncertainty assessment, model calibration and diagnostic evaluation and leading control analysis of PBS models (Pianosi et al. 2016). Raj et al. (2014) performed variancebased sensitivity analysis for NPP and GPP from the Biome-BGC model in Douglas-fir forests, and the findings demonstrated that GPP and NPP were particularly sensitive to the C:N of fine roots and leaves related to the development of the leaf area index. Miyauchi et al. (2019) estimated the carbon density of biomass pools in Eucommia ulmoides plantations on the Loess Plateau and believed that the allocation parameters, along with specific leaf area (SLA) and maximum stomatal conductance $\left(\mathrm{g}_{\mathrm{smax}}\right)$, strongly affected aboveground woody (AC) and leaf carbon (LC) density in a sensitivity analysis. Dagon et al. (2020) developed a machine learning method to proceed with the sensitivity and uncertainty of the community land model parameters, which provided an effective framework in model calibration. The results of site-level sensitivity analysis may not be transferable to other regions owing to the climate, soil, and vegetation types. Comprehensive sensitivity analysis of multiple sites and various methods from PBS models are indispensable to understand the expressions of sensitive parameters among vegetation function types and regions.

Biome-BGCMuSo is a newly developed PBS model from Biome-BGC to simulate carbon, nitrogen, and water fluxes, which improves the phenology, multilayer soil, and management modules (Hidy et al. 2016, 2021). It requires about 82 ecophysiological parameters to characterize the vegetation processes at the site and over large areas. White et al. (2000) performed parameterization and sensitivity analysis on most ecophysiological parameters of BIOME-BGC, and the results provide a valuable reference for the parameterization and calibration of the model (Turner et al. 2005; Shields and Tague 2015; Miyauchi et al. 2019; Neumann et al. 2020). However, the results ignored the parameter differences in different climate zones and mainly analyzed PFT variability. In addition, with the improvement of the model, the influence 
of module coupling on the parameters is unknown. Previous studies suggested that sensitivity analysis results may vary according to specific species and regions (White et al. 2000; Tatarinov and Cienciala 2006; Raj et al. 2014; Miyauchi et al. 2019). This may even influence the calibration procedure of BiomeBGCMuSo for specific species under different environmental and site conditions.

In this paper, we applied regression analysis and EFAST to identify the sensitive parameters of the Biome-BGCMuSo model for GPP and NPP at four sites in China. Our goals are to determine the sensitivity index of input parameters for GPP and NPP and to use this knowledge to gain insight into the capability of the Biome-BGCMuSo model. We aimed to solve the following questions: (1) What are the sensitive parameters for GPP and NPP of different plant functional types (PFTs) in China? (2) How does the response of forest productivity to sensitive parameters change with environmental gradients? This would provide us with informative parameters for further calibration steps and could be extended to the regional scale.

\section{Materials and Methods}

\subsection{Observation sites}

Four observation sites were selected in this study, which were included in ChinaFLUX (Yu et al. 2006, 2016). These sites cover a large range of latitudes (between $42^{\circ} \mathrm{N}$ and $21^{\circ} \mathrm{N}$ ), climate zones and forest species from North to South China (Figure 1). The forest species follow specific latitude patterns, ranging from needle forest and deciduous broad-leaved forests (DBF) in the north to evergreen broadleaved forest (EBF) and evergreen needle-leaved forests (ENF) in the south as well as shrubs in the alpine climate zone on the edge of the Qinghai-Tibetan Plateau (Table 1). Eddy covariance (EC) systems were used to assess the accuracy of Biome-BGCMuSo in simulating GPP and NPP. The observation sites use an open-circuit vorticity correlation system to carry out flux observations and simultaneous gradient observations of conventional meteorological elements. From the ChinaFLUX data, we obtained daily GEE and NEE during the 2003-2010 period for the eddy covariance (EC)-based carbon flux towers at the four observation sites (Zhang et al. 2020; Dai et al. 2020; Wu et al. 2020; Li et al. 2021). The acquired data are based on the ChinaFLUX technology system to complete standardized quality control and data processing. The daily GPP and NPP values were calculated by inverse operation of GEE and NEE. 


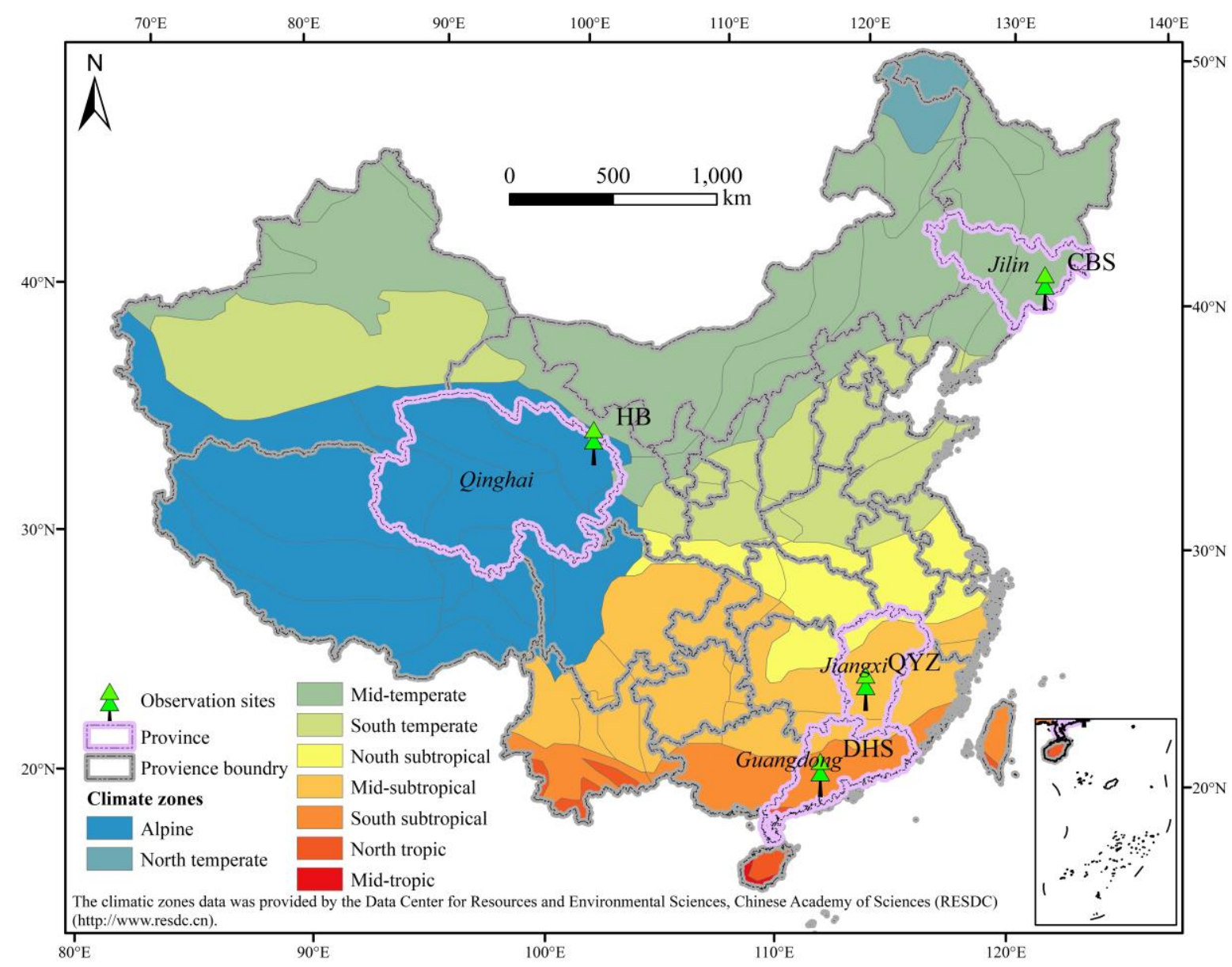

Figure 1. Observation sites and climate zones

The Changbaishan forest site (CBS) is in Jilin Province, with geographic coordinates of $128^{\circ} 05^{\prime} \mathrm{E}$ and $42^{\circ} 24^{\prime} \mathrm{N}$ and an altitude of $738 \mathrm{~m}$. The CBS has a temperate continental climate with significant midlatitude mountain climate characteristics (Chu et al. 2018). It is dry and windy in spring, hot and rainy in summer, and dry and cold in winter, with an average annual temperature of $3.6{ }^{\circ} \mathrm{C}$ and an average annual rainfall of $713 \mathrm{~mm}$. The annual sunshine duration is 2271 2503 hours. The main vegetation is Pinus

111 koraiensis Sieb. et Zucc. and broad-leaved mixed forest on the surface beneath the flux tower. The main

112 tree species are Pinus koraiensis Sieb. et Zucc., Tilia tuan Szyszyl., Quercus mongolica Fisch. ex Ledeb.,

113 Fraxinus mandshurica Rupr., and Acer pictum Thunb. ex Murray, with an average tree height of $26 \mathrm{~m}$

114 (Bai et al. 2014). The average ratio of Pinus koraiensis Sieb. et Zucc. to broad-leaved forest at the CBS

115 site from 2005 to 2010 was 1:9. The soil type is upland dark brown forest soil. The surface organic matter

116 content is approximately $10 \%$. The nitrogen content is approximately $0.3 \%$. In addition, the C:N ratio is 117 approximately $20 \%$, and the clay content is $31 \%$ (Sun et al. 2019).

118 The Haibei grassland site (HB) is in the northeastern part of the Qinghai-Tibetan Plateau. We chose 119 the shrub ecological type at the HB site, with geographic coordinates of $101^{\circ} 19^{\prime} \mathrm{E}$ and $37^{\circ} 39^{\prime} \mathrm{N}$ and an 120 altitude of $3358 \mathrm{~m}$. HB has alpine continental climate characteristics. Restricted by high altitude conditions, 121 the temperature is extremely low. The annual average temperature is $-1.2^{\circ} \mathrm{C}$, the average temperature of 122 the hottest month (July) is $10.4{ }^{\circ} \mathrm{C}$, and the average temperature of the coldest month (January) is $-14.4{ }^{\circ} \mathrm{C}$. 123 The average annual precipitation is $535.2 \mathrm{~mm}$, and the precipitation during the warm season (from May 
124 to September) during the plant growth period is $437.5 \mathrm{~mm}$, accounting for $82 \%$ of the annual precipitation 125 (Li et al. 2019). The annual sunshine duration is $2451.7 \mathrm{~h}$. The dominant and associated species are

126 Potentilla fruticose L. and Kobresia humilis Serg., Festuca ovina L., and Stipa aliena Keng.. At the end 127 of the plant growth period (September), the vegetation coverage can reach approximately $85 \%$ (Li et al. 128 2016). The height of Potentilla fruticosa $\mathrm{L}$. in the upper canopy is approximately $0.6 \mathrm{~m}$, and the average 129 height of the lower herbaceous plants is approximately $0.18 \mathrm{~m}$ (Fu et al. 2006). The main soil type is alpine 130 shrub meadow soil. The organic matter content of the $0-40 \mathrm{~cm}$ soil layer is $11.94 \%$, and the soil nitrogen 131 content is $0.62 \%$ (Hu et al. 2019).

132 The Qianyanzhou forest site (QYZ) is in Jiangxi Province, with geographic coordinates of $115^{\circ} 03^{\prime} \mathrm{E}$ 133 and $26^{\circ} 44^{\prime} \mathrm{N}$. QYZ has typical mid-subtropical monsoon climate characteristics, with a dry winter season 134 and heavy summer rainfall (Yu et al. 2008). The annual average temperature is $17.9^{\circ} \mathrm{C}$, the average annual 135 precipitation is $1542.4 \mathrm{~mm}$, the annual evaporation is $1110.3 \mathrm{~mm}$, and the average annual relative humidity 136 is $84 \%$. Most of the existing forest stands are coniferous forests planted in approximately 1985, and the 137 main tree species are Pinus massoniana Lamb., Pinus elliottii Englem., Cunninghamia lanceolata (Lamb.) 138 Hook. and Schima superba Gardn. et Champ.; evergreen vegetation covers $76 \%$ of the total land area (He 139 et al. 2019). The weathering layer in the QYZ is generally 30 to $50 \mathrm{~cm}$ thick, and the main soil type is 140 typical red earth (Li et al. 2007).

141 The Dinghushan forest site (DHS) is in Guangdong Province, with geographic coordinates of $142112^{\circ} 34^{\prime} 3.8^{\prime \prime} \mathrm{E}$ and $23^{\circ} 10^{\prime} \mathrm{N}$. The altitude is $300 \mathrm{~m}$. DHS in the south subtropical climate zone, with obvious 143 dry and wet seasons. The average annual temperature is $20.9^{\circ} \mathrm{C}$, the average temperature in July is $28.1^{\circ} \mathrm{C}$, 144 and the average temperature in January is $12.0^{\circ} \mathrm{C}$. The average annual precipitation is $1956 \mathrm{~mm}$, and the 145 average annual relative humidity is $82 \%$. The main dominant tree species are Schima superba Gardn. et 146 Champ., Pinus massoniana Lamb. and Castanea henryi (Skam) Rehd. et Wils. (He et al. 2020). The 147 average ratio of EBF to ENF at the DHS site from 2005 to 2010 was 4:6. The soil type is latosolic red soil, 148 and the organic content of the surface layer ranges from $2.94 \%$ to $4.27 \%$ (Zhang et al. 2019).

Table 1 Site descriptions

\begin{tabular}{ccccc}
\hline Sites & CBS & HB & QYZ & DHS \\
\hline Location & $128^{\circ} 05^{\prime} \mathrm{E}$, & $10^{\circ} 19^{\prime} \mathrm{E}$, & $115^{\circ} 03^{\prime} \mathrm{E}$, & $112^{\circ} 32^{\prime} \mathrm{E}$, \\
& $42^{\circ} 24^{\prime} \mathrm{N}$ & $37^{\circ} 39^{\prime} \mathrm{N}$ & $26^{\circ} 44^{\prime} \mathrm{N}$ & $23^{\circ} 10^{\prime} \mathrm{N}$ \\
$\begin{array}{c}\text { Elevation (m) } \\
\text { Climate zone }\end{array}$ & 738 & 3358 & 102 & 300 \\
Temperate & Alpine & Mid-subtropical & $\begin{array}{c}\text { Southern } \\
\text { subtropical }\end{array}$ \\
$\begin{array}{c}\text { Mean annual } \\
\text { Temperature }\left({ }^{\circ} \mathrm{C}\right)\end{array}$ & 3.6 & -1.2 & & 20.9 \\
$\begin{array}{c}\text { Annual } \\
\text { precipitation } \\
(\text { mm })\end{array}$ & 713 & 535.2 & 17.9 & 1956 \\
PFTs & & & & \\
& & & & \\
\end{tabular}




$\begin{array}{ccccc}\begin{array}{c}\text { Canopy height } \\ (\mathrm{m})\end{array} & 26 & 0.6 & 12 & 20 \\ \text { Predominant } & & & & \\ \text { species } & \text { Pinus koraiensis } & \text { Potentilla } & \text { Pinus massoniana } & \text { Schima superba } \\ & \text { Sieb. et Zucc., } & \text { fruticose } \text { L., } & \text { Lamb., Pinus } & \text { Gardn. et Champ., } \\ & \text { Tilia tuan } & \text { Kobresia humilis } & \text { elliottii Englem., } & \text { Pinus massoniana } \\ & \text { Szyszyl., Quercus } & \text { Serg., Festuca } & \text { Cunninghamia } & \text { Lamb., and } \\ & \text { mongolica Fisch. } & \text { ovina } \text { L. } & \text { lanceolata } & \text { Castanea henryi } \\ & \text { ex Ledeb. } & & \text { (Lamb.) Hook. } & \text { (Skam) Rehd. et } \\ & & & & \text { Wils }\end{array}$

\subsection{Biome-BGCMuSo model}

For this work, we used the latest version of Biome-BGCMuSo (V6.1), which was released by the research group of Prof. Zoltán Barcza at the Meteorology Department of Eötvös Lorand University (Hidy et al. 2021). Compared to Biome-BGC, Biome-BGCMuSo is mainly characterized by a multilayer soil module, drought-related plant senescence module, phenology module, and management module (e.g., cropland mowing, grazing, fertilization, harvest and forest thinning). Biome-BGCMuSo also introduced new input variables (for example, measured drain coefficient, hydraulic coefficient, ratio of dry matter and carbon content) and new output parameter variables (cumulative evaporation and transpiration).

The carbon flux module, phenology module and soil flux module are the three most important modules in Biome-BGCMuSo. In the carbon flux module, the photosynthesis program of Farquhar (1980) and the enzyme kinetic model based on Woodrow and Berry (1988) are used to calculate the GPP of the biological community. Autotrophic respiration is divided into maintenance respiration and growth respiration. In addition to temperature, maintenance respiration is a function of the $\mathrm{N}$ content of living plant pools, and growth respiration is a fixed ratio of GPP (Hidy et al. 2016). The phenological module calculates foliage development. There are two models in the phenology module: the optional HSGSI method described in Hidy et al. 2012 and the original Biome-BGC model logic. In this study, we chose the original Biome-BGC model logic since our ecosystem type is forest. The soil flux module describes the decomposition of dead plant material and soil carbon pools. There are three significant developments of the soil flux module in the current model version: standing dead biomass and harvested biomass pools and a ten-layer soil sub-model.

Biome-BGCMuSo uses at least four input files when it is executed: initialization file (INI file), meteorological data file (MET file), soil property file (SOIL file), and a file for ecophysiological constants (EPC file) (Hidy et al. 2021). We elaborated the input files according to the particularity of the observation sites. For the INI file, $\mathrm{CO}_{2}$ and nitrogen deposition are mainly set. The MET file includes the daily values of maximum and minimum air temperatures, precipitation, solar radiation, and vapor pressure deficit. In the SOIL file, we mainly set the soil texture parameters. The EPC file needs to be parameterized according to different PFTs. The detailed data sources and parameterization scheme are described in Section 2.3.

The model simulation is divided into two stages. The first is spinup simulation, which starts with very low initial levels of soil $\mathrm{C}$ and $\mathrm{N}$ and runs until it reaches a steady state under a given climate to estimate 
the initial values of state variables (Thornton and Rosenbloom 2005). Next is the normal simulation, which uses the spinup simulations as the initial values of the $\mathrm{C}$ and $\mathrm{N}$ pools, and the simulation is performed within a predetermined period. Therefore, it is necessary to obtain a long-term series of daily data to drive the whole simulation. In this study, each simulation ran for 36 years from 1975 to 2010, with the first 28 years used as spin-up to bring the model into equilibrium and the last 8 years used for normal running.

\subsection{Input data and parameterization}

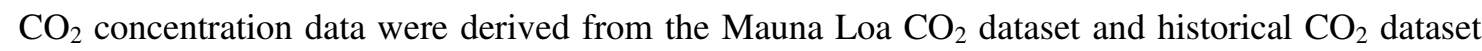
(htp://www.co2.earth). $\mathrm{N}$ deposition was provided by ChinaFLUX (http://rs.cern.ac.cn). The soil texture dataset was provided by the Data Center for Resources and Environmental Sciences, Chinese Academy of Sciences (RESDC) (http://www.resdc.cn). The soil texture data were compiled based on the 1:1 million soil type map and the soil profile data obtained from the second soil survey in China. The soil texture was classified according to the percentage of sand, silt, and clay.

Meteorological data included daily minimum and maximum temperatures, the average daily air temperature, daily precipitation, daily average global radiation, and daily average water vapor pressure difference (VPD). First, we obtained the daily minimum temperature, daily maximum temperature and daily precipitation data from 1982 to 2003 for the four meteorological stations named Changbai $\left(128^{\circ} 11^{\prime} \mathrm{E}\right.$, $\left.41^{\circ} 25^{\prime} \mathrm{N}\right)$, Jiuji $\left(101^{\circ} 29^{\prime} \mathrm{E}, 33^{\circ} 26^{\prime} \mathrm{N}\right)$, Xunwu $\left(115^{\circ} 39^{\prime} \mathrm{E}, 24^{\circ} 57^{\prime} \mathrm{N}\right)$, and Fogang $\left(113^{\circ} 32^{\prime} \mathrm{E}, 23^{\circ} 52^{\prime} \mathrm{N}\right)$ from the China Meteorological Data Network (http://data.cma.cn). These four meteorological stations are close to CBS, HB, QYZ, and DHS. Then, the meteorological station data were converted into the model input meteorological data of the corresponding flux station in the MT-CLIM 4.3 program for the spinup simulation. Finally, the model input meteorological data from 2003 to 2010 were obtained from ChinaFLUX and used for the normal simulation.

A total of 48 parameters in the EPC input file were selected to fluctuate within specific ranges according to the literature. First, basic values were determined by measurements and literature. Then, the variation range of each selected parameter fluctuated by $20 \%$ (White et al. 2000). Because of the individual biochemical and physical constraints, the maximum and minimum values of some parameters constitute the variation ranges. Table 2 shows the candidate input parameters selected in this study and their description information. The basic values and their source information of input parameters for CBS, HB, QYZ and DHS are shown in the Supplementary.

Table 2 Input parameters of Biome-BGCMuSo used in the sensitivity analysis

\begin{tabular}{ccccc}
\hline Number & Parameter & Description & Unit & Varies with PFTs? \\
\hline 1. & TGP & $\begin{array}{c}\text { transfer growth period as a fraction } \\
\text { of the growing season } \\
\text { litterfall as a fraction of the growing } \\
\text { season }\end{array}$ & Prop. & Prop. \\
3. & LGS & LFRT & annual leaf and fine root turnover & Yes \\
& & fraction & Yes \\
4. & LWT & annual live wood turnover fraction & $1 /$ year & No
\end{tabular}


5.

6.

7.

8.

9.

10.

11.

12.

13.

14.

15.

16.

17.

18.

19.

20.

21.

22.

23.

24.

25.

26.

27.

28.

29.

30.

31.

32.

33.

34.

35. NSC: $\mathrm{SC}_{\max }$

k

FLNR

$\mathrm{g}_{\text {smax }}$

$\mathrm{g}_{\mathrm{bl}}$

SW

$\mathrm{R}_{\mathrm{dmax}}$

GR

$\mathrm{MR}_{\text {pern }}$ whole-plant mortality parameter for the vegetation period

$\mathrm{C}: \mathrm{N}$ of leaves

$\mathrm{C}: \mathrm{N}$ of leaf litter

$\mathrm{C}: \mathrm{N}$ of fine roots

$\mathrm{C}: \mathrm{N}$ of fruit

$\mathrm{C}: \mathrm{N}$ of live wood

$\mathrm{C}: \mathrm{N}$ of dead wood

dry matter content of leaves

dry matter content of leaf litter

dry matter content of fine roots

dry matter content of fruit

dry matter content of the soft stem

dry matter content of live wood

dry matter content of dead wood

leaf litter labile proportion

leaf litter cellulose proportion

fine root labile proportion

fine root cellulose proportion

fruit labile proportion

fruit cellulose proportion

dead wood cellulose proportion

canopy water interception

coefficient

canopy light extinction coefficient

fraction of leaf $\mathrm{N}$ in Rubisco

maximum stomatal conductance

boundary layer conductance

stem weight corresponding to

maximum height

maximum depth of the rooting zone

growth resp. per unit of $\mathrm{C}$ grown

maintenance respiration in $\mathrm{kg} \mathrm{C} /$ day
$1 /$ vegetation

Yes

period

$$
\mathrm{kg} \mathrm{C} / \mathrm{kg} \mathrm{N}
$$

Yes

$\mathrm{kg} \mathrm{C} / \mathrm{kg} \mathrm{N}$

Yes

$\mathrm{kg} \mathrm{C} / \mathrm{kg} \mathrm{N}$

Yes

$\mathrm{kg} \mathrm{C} / \mathrm{kg} \mathrm{N}$

Yes

$\mathrm{kg} \mathrm{C} / \mathrm{kg} \mathrm{N}$

Yes

$\mathrm{kg} \mathrm{C} / \mathrm{kg} \mathrm{N}$

Yes

$\mathrm{kg} \mathrm{C} / \mathrm{kg} \mathrm{DM}$

Yes

$\mathrm{kg} \mathrm{C} / \mathrm{kg} \mathrm{DM}$

Yes

Yes

Yes

Yes

Yes

Yes

Yes

Yes

Prop.

Prop.

Yes

Prop.

Yes

Prop.

Yes

Prop.

Yes

Prop.

Yes

1/LAI/d

Yes

DIM

Yes

DIM

Yes

$\mathrm{m} / \mathrm{s}$

Yes

$\mathrm{m} / \mathrm{s}$

Yes

kg C

Yes

m

Yes

Prop.

No

$\mathrm{kg} \mathrm{C} / \mathrm{kg} \mathrm{N} / \mathrm{d}$

No

per kg of tissue $\mathrm{N}$

theoretical maximum prop. of

DIM

No nonstructural and structural

carbohydrates 


\begin{tabular}{|c|c|c|c|c|}
\hline 36. & $\mathrm{NSC}_{\mathrm{MR}}$ & $\begin{array}{c}\text { prop. of nonstructural } \\
\text { carbohydrates available for } \\
\text { maintenance resp. }\end{array}$ & DIM & Yes \\
\hline 37. & $\mathrm{SWC}_{\mathrm{lim} 2}$ & $\begin{array}{l}\text { minimum of soil moisture limit2 } \\
\text { multiplier (full anoxic stress value) }\end{array}$ & Prop. & No \\
\hline 38. & $\mathrm{VPD}_{\mathrm{f}}$ & $\begin{array}{l}\text { vapor pressure deficit: complete } \\
\text { conductance reduction }\end{array}$ & $\mathrm{Pa}$ & Yes \\
\hline 39. & $\mathrm{TR}_{\mathrm{wsl}}$ & $\begin{array}{l}\text { turnover rate of wilted standing } \\
\text { biomass to litter }\end{array}$ & Prop. & Yes \\
\hline 40. & $\mathrm{TR}_{\mathrm{cwl}}$ & $\begin{array}{l}\text { turnover rate of harvested woody } \\
\text { biomass to litter }\end{array}$ & Prop. & No \\
\hline 41. & DTP & $\begin{array}{c}\text { drought tolerance parameter } \\
\text { (critical value of the day since } \\
\text { water stress) }\end{array}$ & day & Yes \\
\hline 42. & SLA1 & $\begin{array}{c}\text { canopy average specific leaf area in } \\
\text { phenological phase } 1\end{array}$ & $\mathrm{~m}^{2} / \mathrm{kg}$ & Yes \\
\hline 43. & SLA2 & $\begin{array}{c}\text { canopy average specific leaf area in } \\
\text { phenological phase } 2\end{array}$ & $\mathrm{~m}^{2} / \mathrm{kg}$ & Yes \\
\hline 44. & SLA3 & $\begin{array}{c}\text { canopy average specific leaf area in } \\
\text { phenological phase } 3\end{array}$ & $\mathrm{~m}^{2} / \mathrm{kg}$ & Yes \\
\hline 45. & SLA4 & $\begin{array}{c}\text { canopy average specific leaf area in } \\
\text { phenological phase } 4\end{array}$ & $\mathrm{~m}^{2} / \mathrm{kg}$ & Yes \\
\hline 46. & SLA5 & $\begin{array}{c}\text { canopy average specific leaf area in } \\
\text { phenological phase } 5\end{array}$ & $\mathrm{~m}^{2} / \mathrm{kg}$ & Yes \\
\hline 47. & SLA6 & $\begin{array}{c}\text { canopy average specific leaf area in } \\
\text { phenological phase } 6\end{array}$ & $\mathrm{~m}^{2} / \mathrm{kg}$ & Yes \\
\hline 48. & SLA7 & $\begin{array}{c}\text { canopy average specific leaf area in } \\
\text { phenological phase } 7\end{array}$ & $\mathrm{~m}^{2} / \mathrm{kg}$ & Yes \\
\hline
\end{tabular}

210 Regression analysis and extended Fourier amplitude sensitivity testing (EFAST) were adapted for the 211 sensitivity analysis of Biome-BGCMuSo, and the contributions of the input parameters to GPP and NPP

212 were quantified. Details of the regression analysis and EFAST methods are provided in subsequent 213 sections.

214 2.4.1 Sensitivity analysis based on regression analysis

215 The basic idea of regression sensitivity analysis is to obtain information about output sensitivity from 216 the statistical analysis of the input data set generated by Monte Carlo simulation (Zagayevskiy and Deutsch 217 2015). Regression analysis derives the sensitivity measure as a parameter of the regression analysis applied 
to the input/output sample set (Hosman et al. 2010; Richard and Christopher 2020). Here, the multiple linear regression method was used to obtain the sensitivity to all single input factors at once. Since the input parameters have different units, the standard regression coefficient is used. The linear least squares estimation of regression coefficients is a measure of sensitivity, and the formula is expressed as

$$
S I_{i}=b_{i} \frac{S D\left(X_{i}\right)}{S D(Y)}
$$

where $S I_{i}$ is the sensitivity of the $\mathrm{i}$-th input parameter, $b_{i}$ is the regression coefficient, $S D\left(X_{i}\right)$ is the standard deviation of multiple sampling of the i-th input parameter, and $S D(Y)$ is the standard deviation of the model's corresponding output Y (NPP and GPP).

\subsubsection{Variance-based sensitivity analysis: EFAST}

EFAST is a global sensitivity analysis algorithm that quantifies the sensitivity of a single parameter and multiple parameters to the outputs (Norton 2015). It is widely used in the sensitivity analysis of nonlinear models, such as Biome-BGC (Yan et al. 2016), crop growth models (Vazquez-Cruz et al. 2014), and building energy models (Nguyen and Reiter 2015). Each input parameter $X_{i}$ has a range of random variables that results in the distribution of an output simulator $\mathrm{Y}$, which can be represented mathematically as

$$
Y=f(X)=f\left(X_{1}, X_{2}, \ldots, X_{i}, \ldots, X_{n}\right)
$$

where $\mathrm{Y}$ is the output (GPP and NPP) of Biome-BGCMuSo. X represents the set of input parameters, and $X_{i}$ is the input parameter with a given upper and lower floating boundary.

EFAST indicates that the variance of the model output can adequately express the uncertainty of the parameter variations in the model results, as shown in equations (3)-(6):

$$
V_{Y}=\sum_{i} V_{i}+\sum_{i} \sum_{j>i} V_{i j}+\sum_{i} \sum_{j>i} \sum_{k>j} V_{i j k}+\cdots \ldots+V_{1,2, \ldots, n}
$$

$$
V_{i}=V\left[E\left(Y \mid X_{i}=x_{i}^{*}\right)\right]
$$

$$
V_{i j k}=V\left[E\left(Y \mid X_{i}=x_{i}^{*}, X_{j}=x_{j}^{*}, X_{k}=x_{k}^{*}\right)\right]-V_{i}-V_{j}-V_{k}
$$

where $V_{Y}$ is the total variance of the model output, and $V_{i}$ is the variance of the conditional expectation (VCE) of Y given that the $\mathrm{i}$-th input Xi has a fixed value $x_{i}^{*} . V_{i j}$ is the VCE of Y given that the $\mathrm{i}$-th input $X_{i}$ has a fixed value $x_{i}^{*}$ and the $\mathrm{j}$-th input $X_{j}$ has a fixed value $x_{j}^{*} . V_{i j k}$ is the VCE of Y given that the inputs $X_{i}, X_{j}$, and $X_{k}$ have fixed values of $x_{i}^{*}, x_{j}^{*}$, and $x_{k}^{*}$, respectively.

Sensitivity is measured by the contribution of a given input factor to the output variance (Pianosi et al. 2016). In this study, we selected the first-order sensitivity index $\left(S_{i}\right)$ and the total sensitivity index $\left(S_{i T}\right)$ to quantify the contributions of the input parameters to the outputs.

The first-order sensitivity index $\left(S_{i}\right)$ measures the direct contribution of each input factor to the output variance or the expected reduction in output variance when a specific input is fixed. It can be represented mathematically as 


$$
S_{i}=\frac{V_{i}}{V_{Y}}
$$

The total sensitivity index $\left(S_{i T}\right)$ can be represented mathematically as

$$
S_{i T}=1-\frac{V\left[E\left(Y \mid X_{-i}=x_{-i}^{*}\right)\right]}{V_{Y}}
$$

In this study, 48 input parameters of Biome-BGCMuSo were evaluated by computing $S I_{i}, S_{i}$ and

$254 S_{i T}$ for the GPP and NPP model outputs. First, according to the range of each input parameter (see

255 Supplementary), the Monte Carlo method was used to uniformly sample each parameter. In this study, the sampling frequency was 4800 (48*100) for each forest PFT. Since CBS and DHS are mixed forests, the total sampling frequency of different PFTs at the 4 observation sites was 28800 (6*4800). According to the generated multiple sets of input parameters, we ran the Biome-BGCMuSo model in batches. GPP and NPP at the observation site from 2003 to 2010 were simulated for the normal stage. Second, the average GPP and NPP were calculated as the final model outputs. The sensitivity results using regression analysis and EFAST were analyzed in the RBBGCMuSo-master R package and SimLab 2.2. Finally, the sensitivity index $\left(S I_{i}, S_{i}\right.$ and $\left.S_{i T}\right)$ was divided into two groups. When the sensitivity index is greater than 0.1 , the corresponding parameter is the sensitive parameter; otherwise, the parameter is not the sensitive parameter. In addition, the key sensitivity parameter refers to the corresponding parameter when $S I_{i}$ and $S_{i T}$ are both greater than 0.1 .

\section{Results}

\subsection{Uncertainty in simulated GPP and NPP}

The uncertainty of GPP and NPP from the input data was calculated using EFAST. Figure 2 shows the distribution of GPP. Generally, the GPP value of subtropical forests (QYZ and DHS sites) was higher than that of other forest sites. The GPP distribution of shrubs was relatively scattered, while that of ENF was relatively concentrated. QYZ with planted ENF and DHS with EBF had obvious discrete values. Table 3 shows the statistical data of the annual average GPP for forest PFTs at the observation sites. The uncertainty (coefficient of variation, CV) of GPP in DBF was greater than that in ENF. The CV of DBF at CBS was $39 \%$, with a range of $168-1383 \mathrm{~g} \mathrm{C} / \mathrm{m}^{2} / \mathrm{a}$ for GPP. The uncertainty of ENF at CBS was $9 \%$, with a range of 1417-2641 $\mathrm{g} \mathrm{C} / \mathrm{m}^{2} / \mathrm{a}$ for GPP. The uncertainty of GPP in planted forests was higher than that in natural forests, and the CVs of ENF at QYZ and DHS were $11 \%$ and 4\%, respectively. In general, the uncertainty of temperate forest sites was higher than that in other climatic zones.

As shown in Figure 3, ENF at the CBS site had the highest NPP. The QYZ forest site with planted ENF had the most discrete NPP. The highest NPP uncertainty occurred in the DBF type (with CV=41\%), which was similar to GPP (Tables 3 and 4).

Both GPP and NPP for ENF at the QYZ forest site had obvious discrete values. The amounts of GPP and NPP distributed in the ranges of 1842-3200 $\mathrm{g} \mathrm{C} / \mathrm{m}^{2} / \mathrm{a}$ and 200-400 g C/m²/a were zero, respectively. These findings illustrated that under certain parameter combinations, forests experience unsustainable or disturbed growth during years of model simulation. However, the sensitivity analysis was not affected by 

the above conditions due to the available and useful spinup phase, and it also explained that the sensitive parameters led to the scattered distribution of GPP and NPP values.

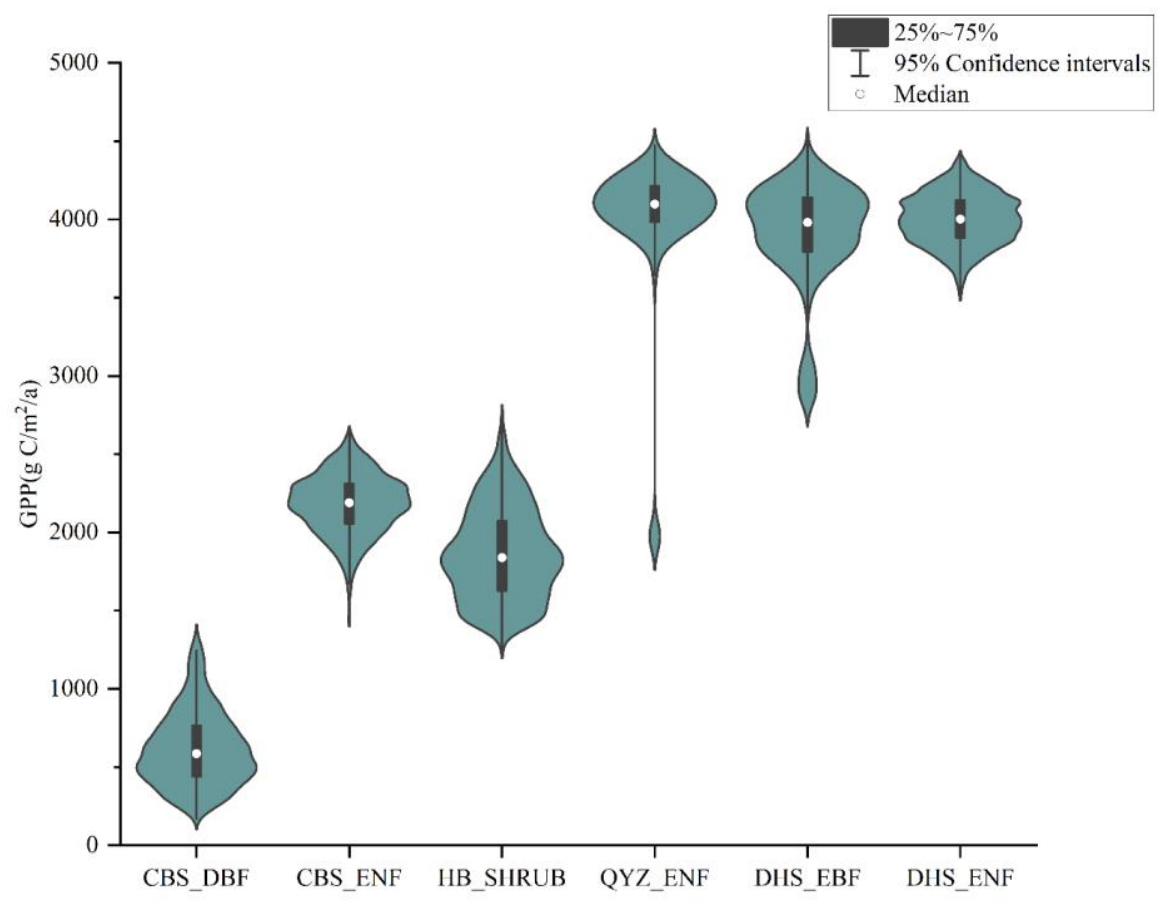

Figure 2 The distribution of the annual average GPP for forest PFTs at the observation sites

Table 3 The statistical table of the annual average GPP for forest PFTs at the observation sites

\begin{tabular}{ccccccc}
\hline Statistics & \multicolumn{2}{c}{ CBS } & HB & QYZ & \multicolumn{2}{c}{ DHS } \\
\cline { 2 - 7 } & DBF & ENF & SHRUB & ENF & EBF & ENF \\
\hline Min. & 168 & 1417 & 1236 & 1842 & 2195 & 3485 \\
Max. & 1383 & 2641 & 2818 & 4471 & 4567 & 4409 \\
Mean & 617.6 & 2180.96 & 1863.43 & 4013.35 & 3913.94 & 4001.84 \\
SD & 238.28 & 189.54 & 294.45 & 455.54 & 341.73 & 163.12 \\
CV (\%) & 39 & 9 & 16 & 11 & 9 & 4 \\
\hline
\end{tabular}




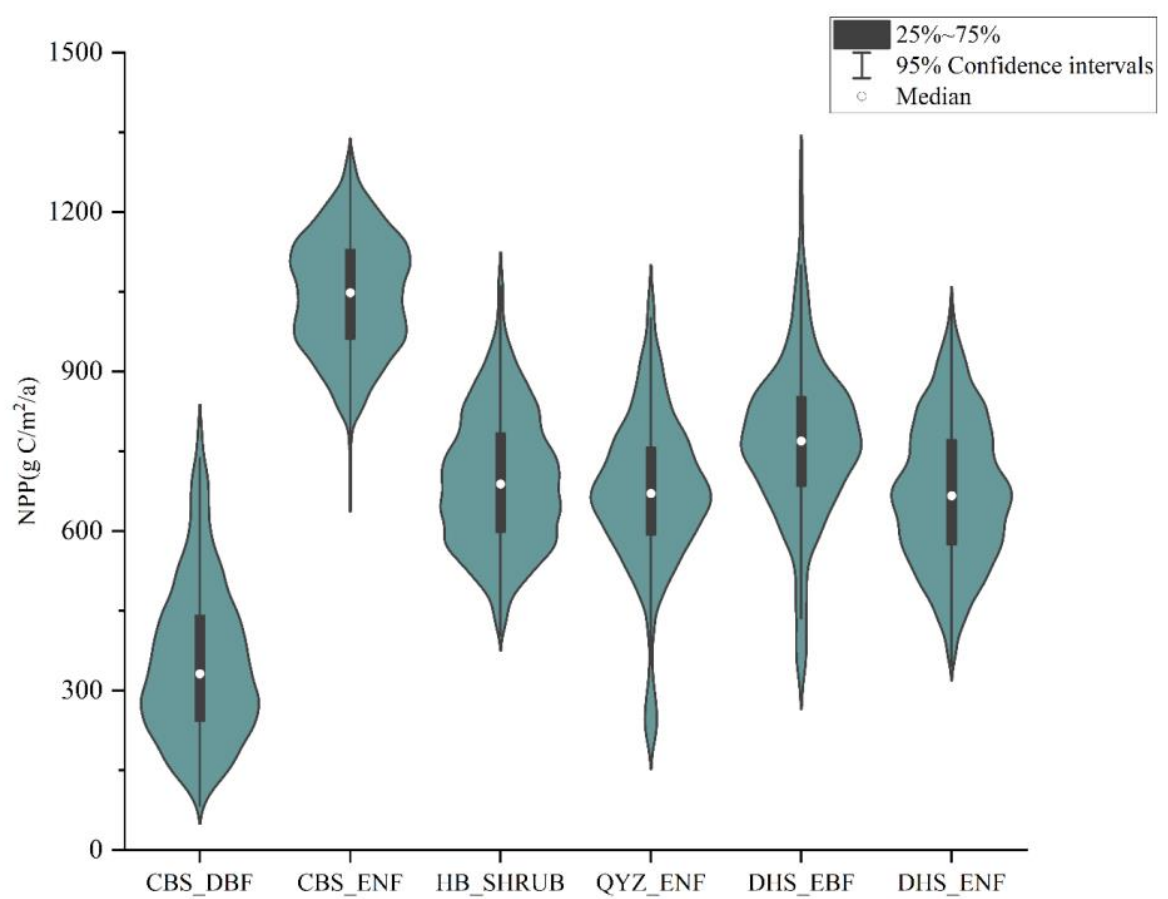

Figure 3 The frequency distribution histogram of the annual average NPP for forest PFTs at the observation sites

Table 4 The statistical table of the annual average NPP for forest PFTs at the observation sites

\begin{tabular}{ccccccc}
\hline Statistics & \multicolumn{2}{c}{ CBS } & HB & QYZ & \multicolumn{2}{c}{ DHS } \\
\cline { 2 - 7 } & DBF & ENF & SHRUB & ENF & EBF & ENF \\
\hline Min. & 83 & 648 & 403 & 163 & 291 & 347 \\
Max. & 823 & 1318 & 1115 & 1088 & 1336 & 1054 \\
Mean & 352.12 & 1044.90 & 695.64 & 669.45 & 766.29 & 672.30 \\
SD & 143.75 & 109.47 & 125.28 & 146.08 & 148.96 & 132.86 \\
CV (\%) & 41 & 10 & 18 & 22 & 19 & 20 \\
\hline
\end{tabular}

As mentioned in 2.4.2, sensitive parameters were those with $S I_{i}$ greater than 10\%. Figures 4(a) and 4(b) show the sensitive parameters of GPP and NPP calculated by regression analysis.

Overall, both GPP and NPP were sensitive to 8 parameters: $C: \mathrm{N}_{\text {leaf }}, \mathrm{W}_{\mathrm{int}}, \mathrm{k}, \mathrm{FLNR}, \mathrm{GR}, \mathrm{MR}_{\text {pern }}, \mathrm{VPD}_{\mathrm{f}}$, and SLA1. Specifically, $\mathrm{MR}_{\text {pern }}$ was the parameter with maximum sensitivity for ENF and EBF types, especially in subtropical climate zones. At the shrub site, both GPP and NPP were sensitive to $\mathrm{W}_{\text {int }}$ and SLA1, which was completely different from the other forest sites. Notably, one major difference in the sensitive parameters between GPP and NPP was $\mathrm{C}: \mathrm{N}_{\mathrm{fr}}$, that is, NPPs for all observation sites were not sensitive to $\mathrm{C}: \mathrm{N}_{\mathrm{fr}}$.

The sensitive parameters varied with different climatic zones. In temperate zone, FLNR was the common sensitive parameter for DBF and ENF, with respective $S I_{i}$ values of $15.8 \%$ and $28.88 \%$ for GPP and $14.3 \%$ and $30.5 \%$ for NPP. In the alpine zone, GPP and NPP were severely restricted by $\mathrm{W}_{\text {int. }}$ This may be because $\mathrm{W}_{\mathrm{int}}$ controls the percentage of precipitation that enters the soil water pool and that is 
transpired, while $\mathrm{HB}$ had the lowest precipitation among the four observation sites, and $\mathrm{W}_{\text {int }}$ in turn became the main limiting factor in those water-stressed regions. In the subtropical zone, different PFTs also showed similar sensitive parameter combinations. $\mathrm{C}: \mathrm{N}_{\text {leaf }}$ exerted a significant control on GPP and NPP for all PFTs except the most sensitive parameter $\mathrm{MR}_{\text {pern. }} \mathrm{C}: \mathrm{N}_{\text {leaf }}$ directly affects the distribution of carbon and nitrogen in leaves and then affects photosynthesis and cumulative productivity.

For different PFTs, individual parameters had a large impact on specific PFTs. Shrubs were most sensitive to $\mathrm{W}_{\text {int }}$ (GPP: 38\%; NPP: 38.7\%) and SLA1 (GPP: 31.9\%; NPP: 31.2\%). For the evergreen types, $\mathrm{MR}_{\text {pern }}$ was the most sensitive parameter, which mainly controlled plant growth. For DBF, VPD $\mathrm{f}_{\mathrm{f}}$ exhibited very high sensitivity, with $50.4 \%$ and $49.7 \%$ for GPP and NPP, respectively.

(a)

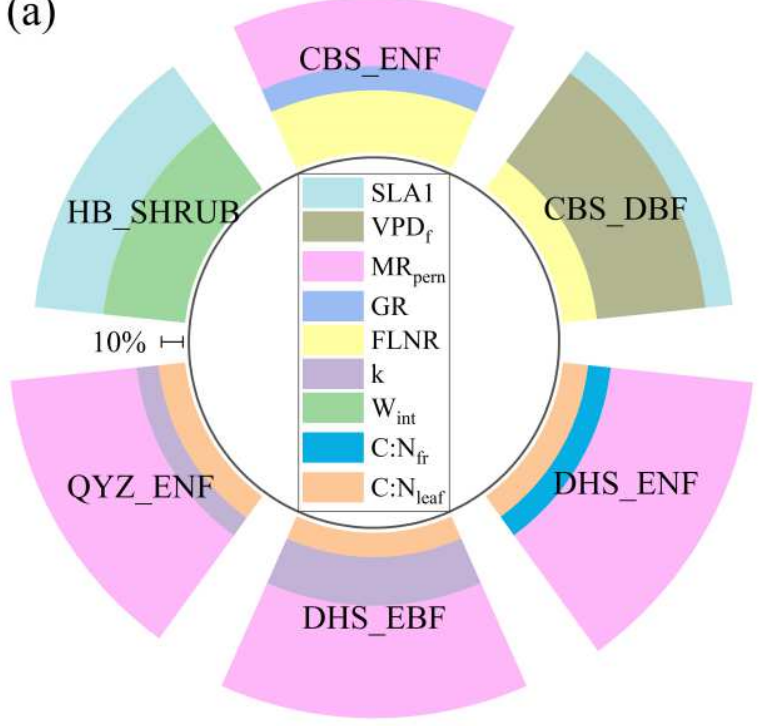

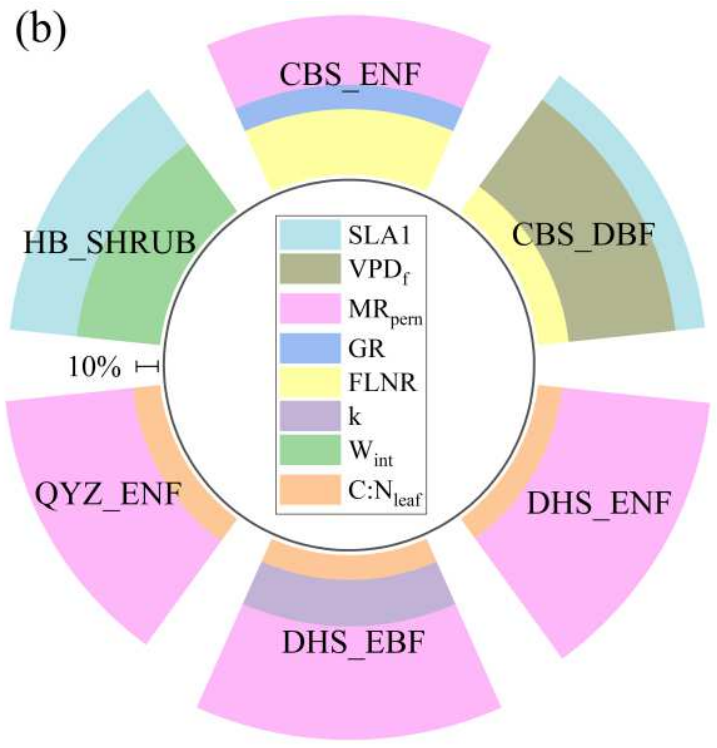

Figure 4 The $S I_{i}$ of GPP (a) and NPP (b) at the observation sites

\subsection{EFAST for GPP and NPP}

The first-order sensitivity index $\left(S_{i}\right)$ and total sensitivity index $\left(S_{i T}\right)$ of the selected parameters for GPP and NPP at the four observation sites are shown in Figure 5 and Figure 6. Sensitive parameters were shown above the red dashed line.

As shown in Figure 5 and Figure $6, S_{i}$ and $S_{i T}$ of $\mathrm{VPD}_{\mathrm{f}}, \mathrm{W}_{\text {int }}$, SLA1, and k were similar for GPP and NPP, which controlled GPP and NPP either directly or through interaction. FLNR was the common sensitive parameter in the temperate zone (CBS site). DBF and ENF at CBS site were most influenced by $\mathrm{VPD}_{\mathrm{f}}$ and $\mathrm{W}_{\mathrm{int}}$, respectively. For the unique shrub site, SLA1 was the most sensitive parameter for GPP. k displayed the highest $S_{i}$ and $S_{i T}$ in subtropical zones (QYZ and DHS sites). MR pern exerted a significant control on NPP for all PFTs except shrubs. More sensitive parameters appeared in the total sensitivity index than those in $S_{i}$ for the QYZ and DHS sites. This indicated that numerous parameters strongly influenced GPP only through interactions. 


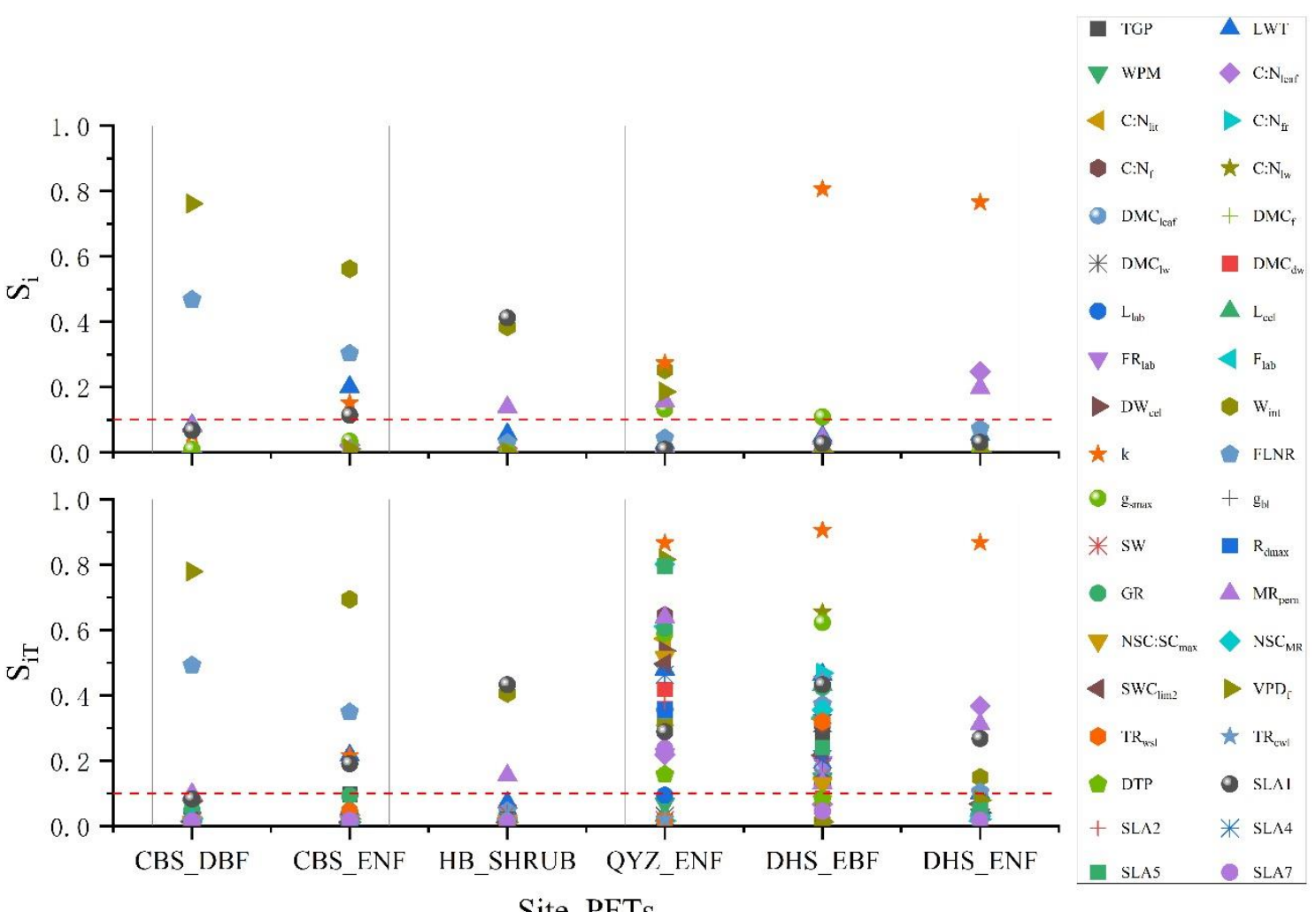

Site PFTs

Figure 5 EFAST sensitivity analysis results of GPP at the observation sites

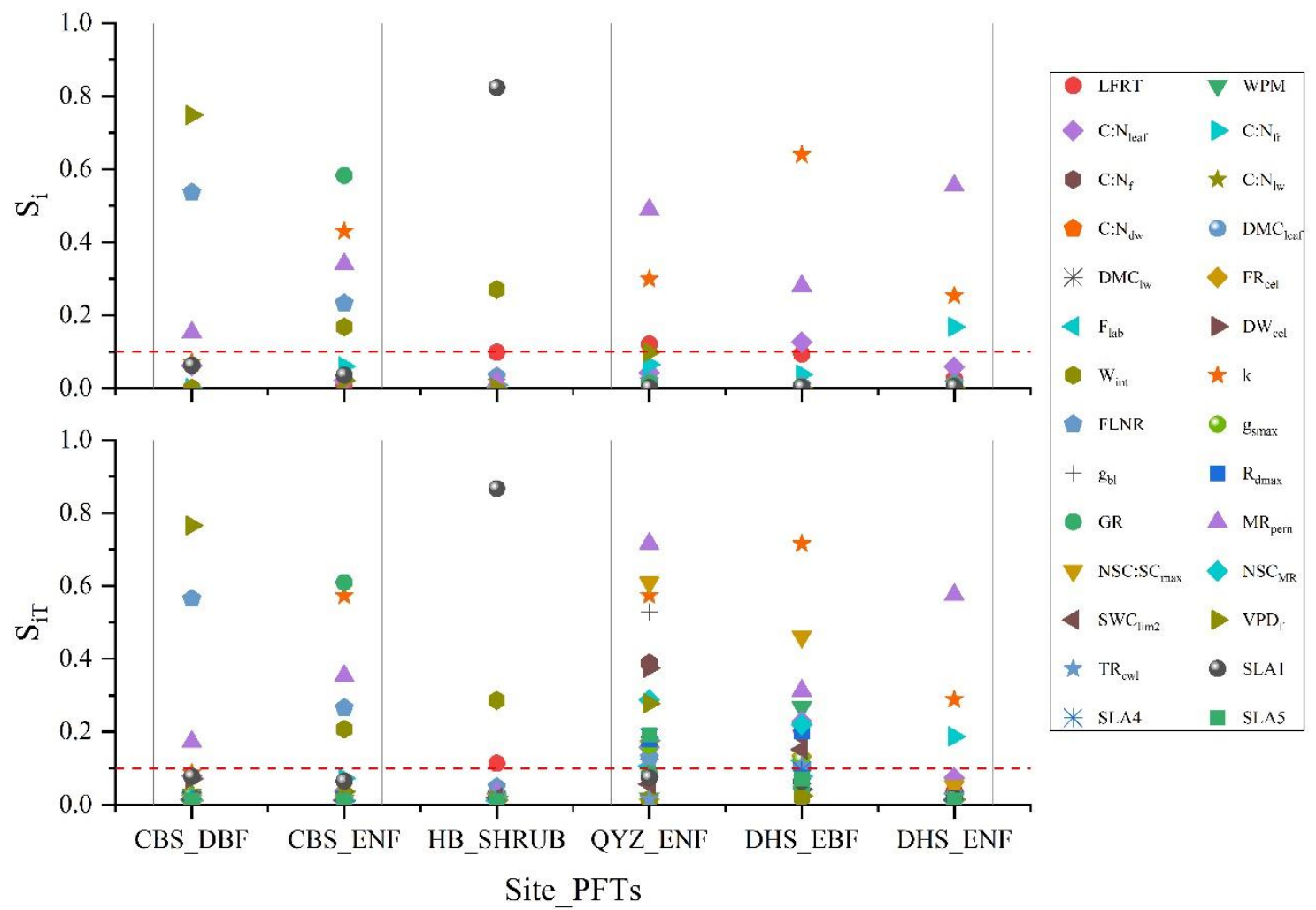

Figure 6 EFAST sensitivity analysis results of NPP for forest PFTs at the observation sites 
Seven key sensitive parameters for GPP and NPP were summarized from the two sensitivity analysis methods: C: $\mathrm{N}_{\text {leaf }}, \mathrm{W}_{\text {int }}, \mathrm{k}, \mathrm{FLNR}, \mathrm{MR}_{\mathrm{pern}}, \mathrm{VPD}_{\mathrm{f}}$, and SLA1 (Figure 7 and Figure 8). The sensitive parameters selected by regression analysis were similar to those from EFAST, and the key sensitive parameters differed significantly under various climate environments and PFTs. FLNR was the key sensitive parameter in temperate zone, and $\mathrm{C}: \mathrm{N}_{\text {leaf }}$ was the key sensitive parameter in subtropical zones. $\mathrm{VPD}_{\mathrm{f}}$ was the key sensitive parameter for DBF, and GR was the key sensitive parameter for ENF at the CBS site. At the DHS site, C: $\mathrm{N}_{\text {leaf }}$ and $\mathrm{k}$ were the key sensitive parameters of EBF, and $\mathrm{C}: \mathrm{N}_{\text {fr }}$ was the key sensitivity parameter of ENF. In addition, $\mathrm{C}: \mathrm{N}_{\text {fr }}$ was the sensitive parameter only for ENF-type GPP at the DHS site, while GR was the sensitive parameter only for ENF-type NPP at the CBS site.

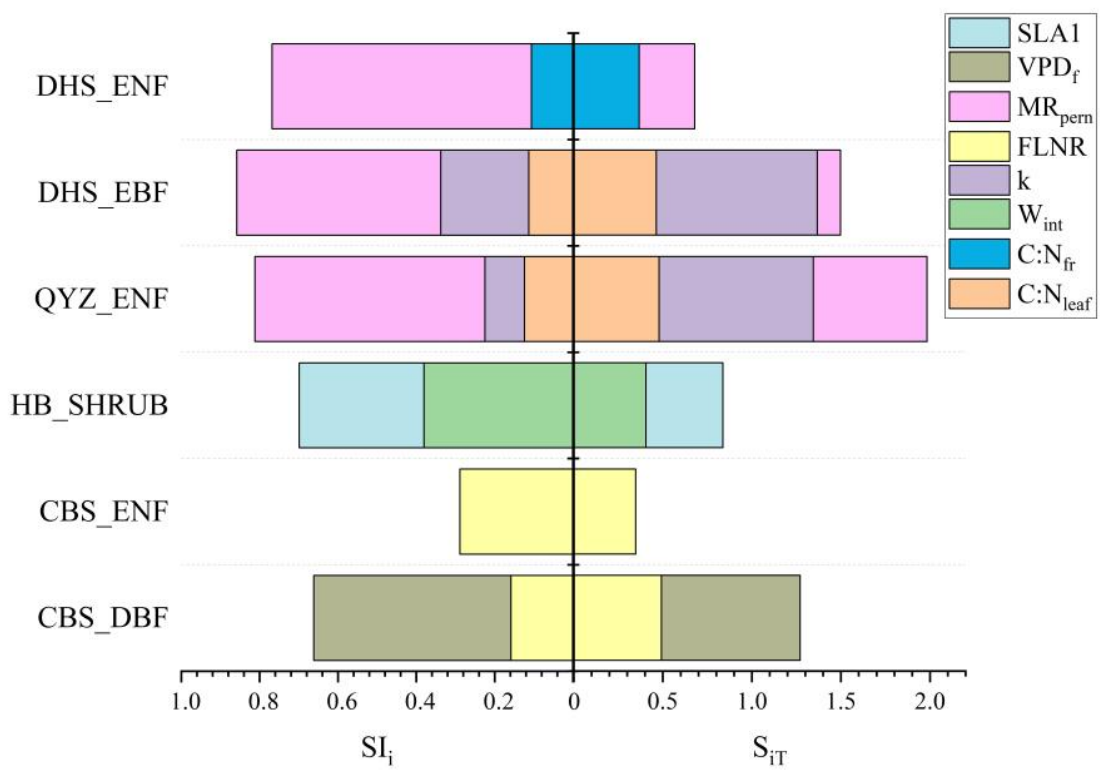

Figure 7 The key sensitivity parameters of GPP for different forest PFTs at the observation

sites

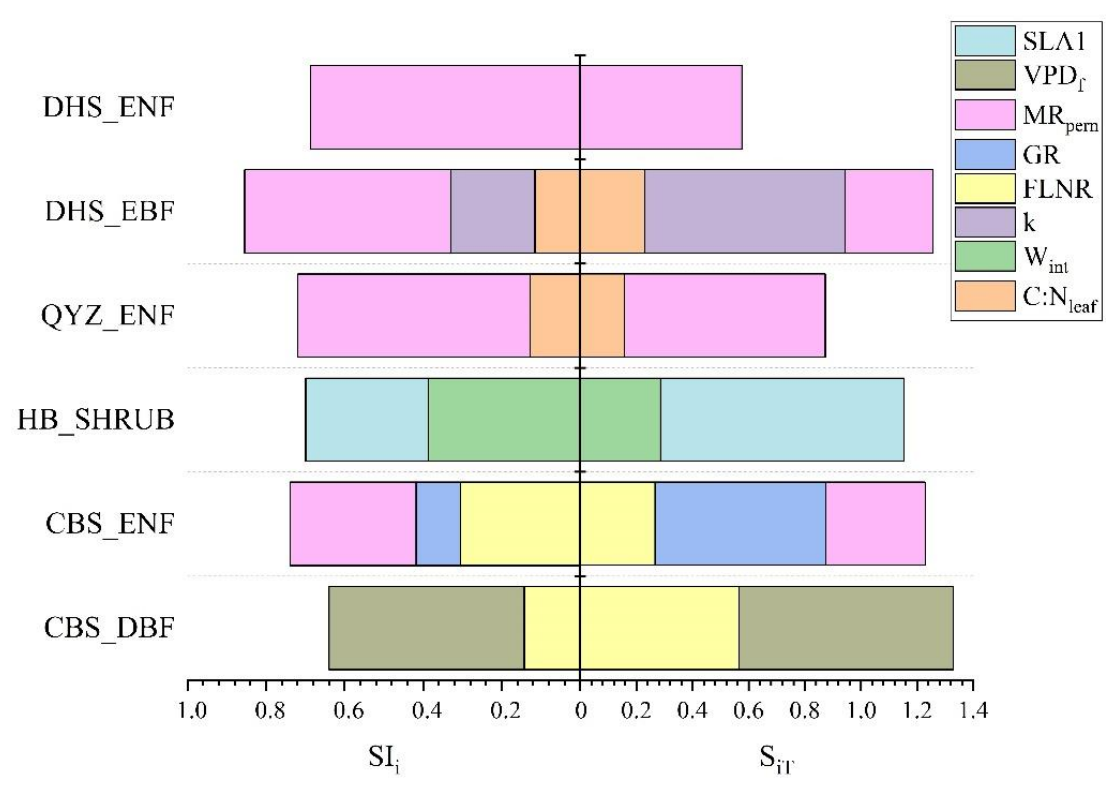

Figure 8 The key sensitivity parameters of NPP for different forest PFTs at the observation 


\subsection{A framework for optimizing forest primary productivity parameters based on sensitivity analysis}

The key sensitive parameters extracted according to different sensitivity analysis methods have a high degree of similarity. It is therefore necessary to perform a series of steps for key sensitivity parameters to simplify the process from sensitivity analysis to parameter correction. Here, we refer to these steps as the "workflow". The workflow for the application of key parameters is shown in Figure 9. The colored parameters should be of importance in sensitivity analysis and modeling. We described and discussed the workflow and the choices that the user must make in each step to provide practical guidelines to support the user in the sensitivity analysis-based simulation correction of the parameters.

The most important thing in the experimental design of sensitivity analysis is to determine the parameters and sensitivity analysis methods. These together constitute what we call the "experimental settings." Specifically, the chosen parameters include (i) selecting the input factors to be accepted by the sensitivity analysis and their floating intervals and (ii) setting the values of other input factors, and these input factors will remain constant throughout the sensitivity analysis. The selection of sensitivity analysis methods can be found in the application process of sensitivity analysis proposed by Pianosia et al. (2016).

The results described in sections 3.2 and 3.3 indicate that the sensitivity of the climate environment to productivity simulation is greater than the difference in PFTs. Specifically, the most common sensitivity parameter of different PFTs in the temperate zone was FLNR, followed by $\mathrm{MR}_{\text {pern. }}$ In the alpine zone, the common sensitive parameters of different PFTs were SLA1 and $\mathrm{W}_{\text {int. }}$ In addition, C: $\mathrm{N}_{\text {leaf }}$ was the key sensitive parameter for different PFTs in the subtropical zone, followed by $\mathrm{MR}_{\text {pern }}$. Next was the selection of key sensitive parameters for different PFTs. In the temperate zone, DBF was sensitive to $\mathrm{VPD}_{\mathrm{f}}$, and ENF was sensitive to GR. In the subtropical zone, EBF was sensitive to k, and ENF was sensitive to C: $\mathrm{N}_{\mathrm{fr}}$. In addition, GR and C: $\mathrm{N}_{\text {fr }}$ were the key sensitive parameters of NPP and GPP, respectively, excluding the common key sensitive parameters of NPP and GPP. As the importance of the parameters gradually decreases with the deepening of the workflow, the disturbance effect of the following parameters on the simulation results gradually decreases. In the application workflow for key parameters, if some key sensitive parameters (such as GR and $\mathrm{C}: \mathrm{N}_{\mathrm{fr}}$ ) have been added before, the corresponding steps can be omitted in the following process.

The uncertainty discussed in Section 3.1 is intended to assess the uncertainty of the results of a particular sensitivity analysis method, therefore providing information on the reliability of the results within the scope of the method. A different and equally relevant question is the degree to which the method itself can be trusted, that is, whether the method is suitable for solving the expected answer when applied to the immediate question. For example, variance-based sensitivity analysis methods rely on the assumption that variance is a wise substitute for uncertainty and may not be correct for highly skewed

384 output distributions. In this case, even if researchers can obtain an almost completely accurate estimate of 385 the sensitivity index based on variance, they cannot provide a correct ranking (Liu et al. 2005). Therefore, 386 the sensitivity analysis results may be very reliable, but they still need to be based on actual conditions. 
Circumstances evaluate the accuracy of the results and explain the reasonableness of the sensitivity analysis results.

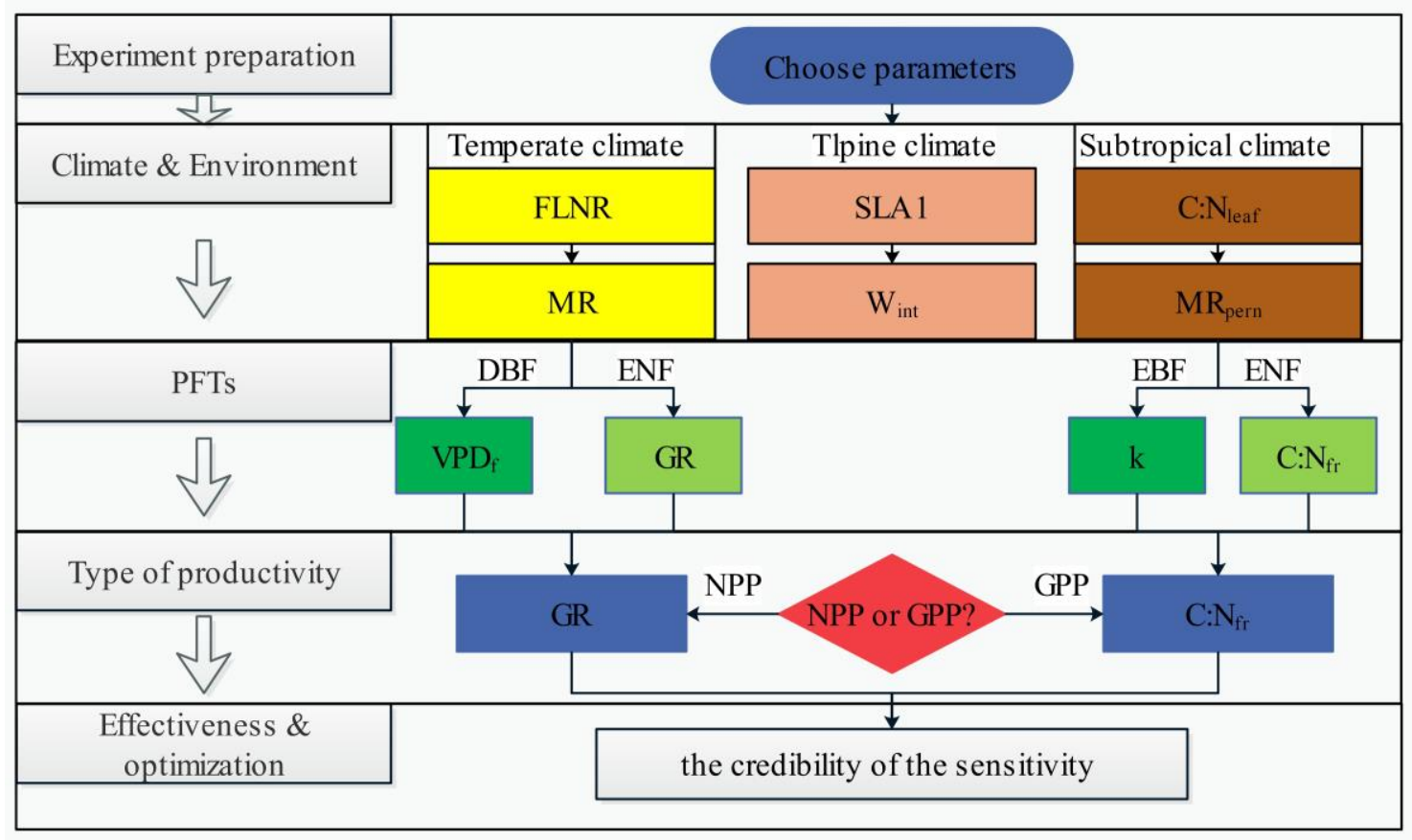

Figure $9 \mathrm{~A}$ framework for optimizing forest primary productivity parameters based on sensitivity

analysis

\subsection{Uncertainty of the input parameters}

The use of the input parameter values of a specific site can achieve the best simulation and a relatively high degree of acceptance of the sensitivity analysis results (Thornton et al. 2002; Toriyama et al. 2021). There are two main limitations: (1) Some input parameters cannot be directly observed, such as FLNR and parameters related to decomposition and distribution $\left(\mathrm{L}_{\mathrm{lab}}, \mathrm{L}_{\mathrm{cel}}\right)$. (2) The variation range of parameters is difficult to obtain. In this study, the main parameters related to $\mathrm{C}$ and $\mathrm{N}$ allocation, plant height, and root depth were obtained from actual measurements or research at the observation sites. Parameter localization was carried out based on the model default parameters (see Supplementary).

To explore the impacts of different basic values of the parameters on outputs, we analyzed the simulated GPP of the CBS site under three schemes: (1) default parameters; (2) localized parameters; and (3) corrected parameters based on sensitivity analysis. The results were validated against EC measurements, as shown in Figure 10. Rows (a), (b) and (c) represent different PFTs of the mixed forest, DBF and ENF, respectively. The results show that the model calibrated by sensitivity analysis had the best simulation compared with EC measurements, especially for ENF, with $\mathrm{R}^{2}=0.69$, which improved by $16 \%$ and $10 \%$ compared to schemes 1 and 2 . The sensitive parameters control the key processes associated with the GPP simulation. By correcting related sensitive parameters, the uncertainty of input parameters can be effectively reduced, and the simulation accuracy of the process model can be improved. 

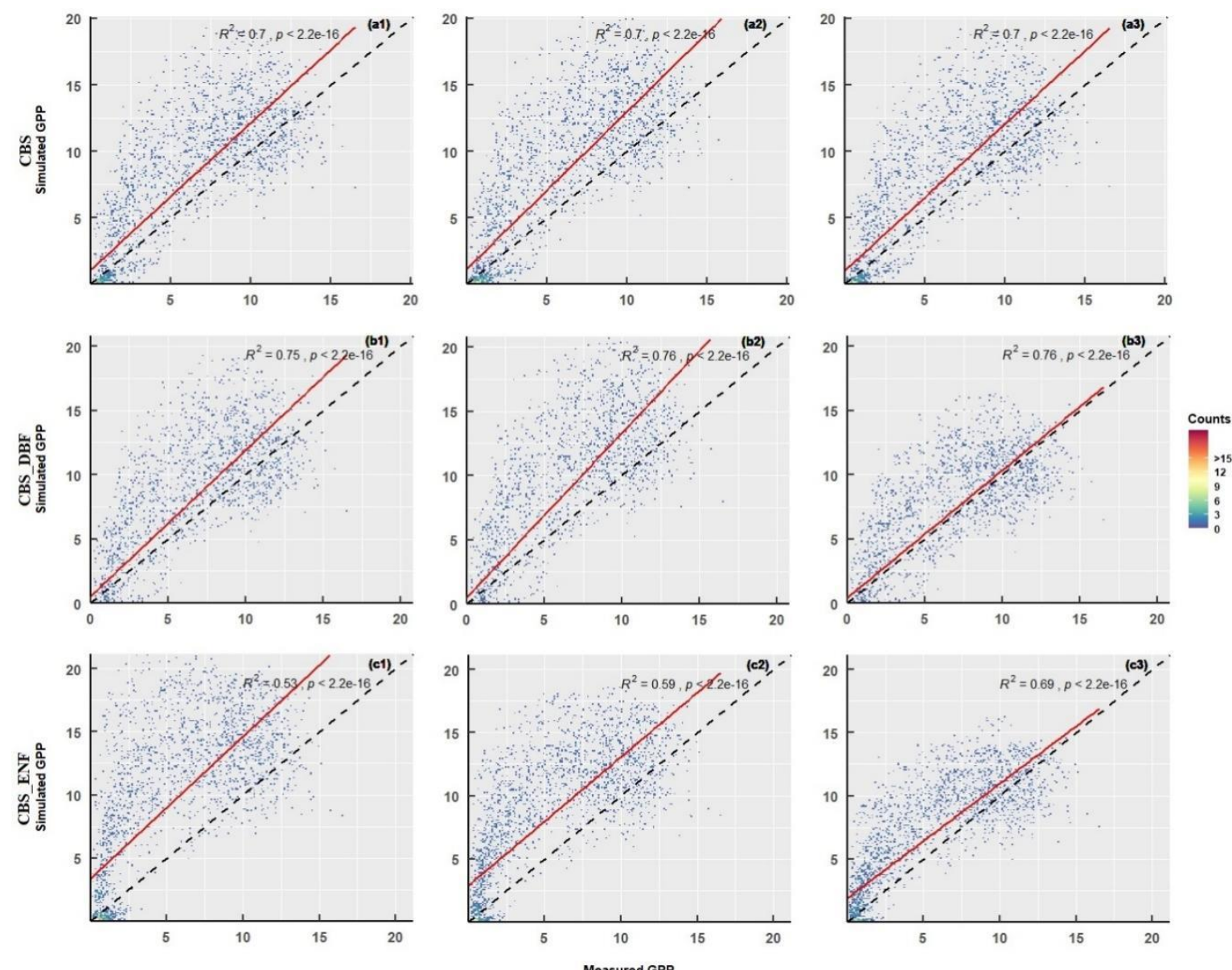

Figure 10 Correlation analysis of simulated GPP and vorticity flux observation values under three parameterization schemes at the CBS site

Previous studies showed that parameters with smaller basic values were more susceptible to the influence of the parameter range, and a narrow range would limit the sensitivity index of a small parameter (Ma et al. 2020). Therefore, the range of the parameter is crucial to the result of the sensitivity analysis. In this study, under the premise of giving priority to physical or biological constraints, the localized parameters are all taken as the parameter perturbation range with fluctuations of $20 \%$ (White et al. 2000). The consistency of the parameter range is guaranteed to a certain extent.

\subsection{Sensitive parameters}

According to recent studies, it was predicted that forest carbon sequestration decreased with increasing carbon dioxide and would possibly be a carbon source in the future (Cox et al. 2000; Baccini et al. 2017; Brienen et al. 2020). In contrast, some studies demonstrated that the absorption capacity of forest carbon sinks would continue (Wang et al. 2020; Harris et al. 2021; Heinrich et al. 2021). This means that considerable uncertainties exist during carbon flux simulation and even the climate-forest carbon cycle feedback mechanism. Therefore, sensitivity analysis was applied in this study, aiming to distinguish the model's influential parameters and examine carbon flux output sensitivity.

Our results showed that 7 parameters had important impacts on both GPP and NPP. However, many parameters in BIOME-BGCMuSo exhibited extremely low sensitivity for GPP and NPP, for example, 
LGS (litterfall as a fraction of the growing season), LWT (annual live wood turnover fraction), and parameters related to the dry matter content $\left(\mathrm{DMC}_{\text {lit }}\right.$ (dry matter content of leaf litter), $\mathrm{DMC}_{\mathrm{f}}$ (dry matter content of fruit), and $\mathrm{DMC}_{\mathrm{dw}}$ (dry matter content of dead wood)). The parameters that most influenced GPP and NPP were those controlling respiration and the assimilation rate of photosynthesis, such as MR $_{\text {pern }}$,

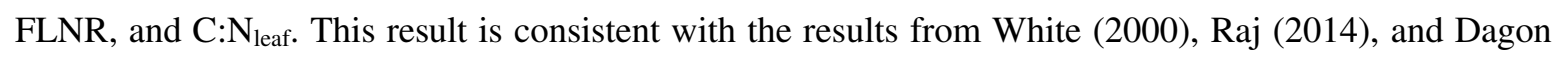
(2020). $\mathrm{MR}_{\text {pern }}$ represents the maintenance respiration in $\mathrm{kg} \mathrm{C} /$ day per $\mathrm{kg}$ of tissue $\mathrm{N}$, which is directly related to maintenance respiration and further affects GPP and NPP (Ryan 1991). FLNR controls the potential rate of carboxylation and directly affects $\mathrm{VC}_{\max }$; therefore, it is a dominant control of canopy assimilation (White et al. 2000; Stitt and Schulze 1994). C: $\mathrm{N}_{\text {leaf }}$ is a compound parameter that determines the important factors of the nitrogen required to construct leaves, the amount of nitrogen available for investment in photosynthetic machinery, and leaf respiration rates.

The sensitive parameters varied under different climate and environmental conditions. FLNR had a strong influence on GPP and NPP in the temperate zone; $\mathrm{C}: \mathrm{N}_{\text {leaf }}$ was sensitive in the subtropical zone. This indicated the limiting effects of light, water, temperature and mineral nutrients on primary productivity under different climatic environments in previous studies (Knapp et al. 2014). In addition, many studies have shown that leaf traits change significantly along temperature and rainfall gradients (Domínguez et al. 2012; Wright et al. 2017). As the latitude increases, Rubisco activity is significantly inhibited, which affects FLNR and inhibits the assimilation of C. In contrast, the temperature weakly restricts the activity of Rubisco in subtropical areas. This may explain why FLNR has high sensitivity in the temperate zone. $\mathrm{C}: \mathrm{N}_{\text {leaf }}$ is directly related to the nitrogen content in the leaves. The nitrogen content directly affects the content of chlorophyll, thereby affecting photosynthesis. Gong et al. (2020) investigated the leaf traits of different life forms at different latitudes in northeastern China and found that nitrogen was limited in low latitude areas and that leaf traits were very sensitive to climate factors. Our results clarify the key sensitivity parameters of GPP and NPP in different climatic environments and provide information for the accurate simulation and parameter correction of GPP and NPP at regional scale.

\section{Conclusions}

Two sensitivity analysis methods, regression analysis and EFAST, were used in this work to determine the key parameters of the Biome-BGCMuSo model. The key sensitivity parameters extracted according to different sensitivity analysis methods had a high degree of similarity. The results demonstrated that $\mathrm{C}: \mathrm{N}_{\text {leaf }}, \mathrm{W}_{\text {int }}, \mathrm{k}, \mathrm{FLNR}, \mathrm{MR}_{\text {pern }}, \mathrm{VPD}_{\mathrm{f}}$, and SLA1 were the most sensitive parameters for GPP and NPP. Specifically, GPP and NPP were most sensitive to FLNR, SLA1 and Wint, and C: $\mathrm{N}_{\text {leaf }}$ in temperate, alpine and subtropical zones, respectively. Finally, we suggested a framework of sensitivity analysis by considering different climate conditions, which would present a reliable solution of decreasing the complexity of calibrating process-based models. We emphasize that the calibration of parameters should be based on PFTs, and more attention should be paid to the differences in climate and environment.

\section{Abbreviations}




\begin{tabular}{ll}
\hline GPP & Gross primary productivity \\
NPP & Net primary productivity \\
PFTs & Plant functional types \\
PBS & Process-based simulation \\
CBS & Changbaishan site \\
HB & Haibei site \\
QYZ & Qianyanzhou site \\
DHS & Dinghushan site \\
DBF & Deciduous broad-leaved forests \\
ENF & Evergreen needle-leaved forests \\
EBF & Evergreen broad-leaved forests \\
Prop. & Proportion \\
DIM & Dimensionless \\
DM & Dry matter \\
VC & Maximum carboxylation rate \\
\hline
\end{tabular}

464 Note: The abbreviated representation and description of the model input parameters are shown in Table 2.

465 Declarations

466 Ethics approval and consent to participate

$467 \quad$ Not applicable

468 Consent for publication

$469 \quad$ Not applicable

470 Availability of data and materials

471 The datasets used or analyzed during the current study are available from the corresponding author 472 on reasonable request.

\section{Competing interests}

$474 \quad$ The authors declare that they have no competing interests

$475 \quad$ Funding

476 This study was funded by the National Natural Science Foundation of China (grant 477 number 41901364 and 41871279).

\section{Authors' contributions}

Hongge Ren and Li Zhang devised the main theoretical framework and proof outline. Hongge Ren 480 performed the analytic calculations and model simulations and took the lead in writing the manuscript. 481 Min Yan and Xin Tian provided significant feedback and helped shape the research, analysis and 482 manuscript. Xingbo Zheng provided some of the climate data for the research. All authors read and 483 approved the final manuscript. 


\section{Acknowledgments}

Biome-BGCMuSo was developed from the widely used Biome-BGC model that was created by the Numerical Terradynamic Simulation Group (NTSG), University of Montana. We thank all the scientists, software engineers, and administrators who contributed to the development of Biome-BGC and BiomeBGCMuSo 6.1. We thank ChinaFLUX for providing long-term monitoring data of the forest ecosystem at the observation sites, such as phenology, plant community composition, mineral element content and energy of dominant plants and litter of the forest plant community.

\section{References}

Baccini A, Walker W, Carvalho L, et al (2017) Tropical forests are a net carbon source based on aboveground measurements of gain and loss. Science 358:230-234. https://doi.org/10.1126/science.aam5962

Bai E, Li W, Li S, et al (2014) Pulse Increase of Soil N2O Emission in Response to N Addition in a Temperate Forest on Mt Changbai, Northeast China. PLoS ONE 9:1-9. https://doi.org/10.1371/journal.pone.0102765

Brienen RJW, Caldwell L, Duchesne L, et al (2020) Forest carbon sink neutralized by pervasive growthlifespan trade-offs. Nat Commun 11:4241. https://doi.org/10.1038/s41467-020-17966-Z

Chu C, Lutz JA, Král K, et al (2018) Direct and indirect effects of climate on richness drive the latitudinal diversity gradient in forest trees. Ecol Lett 245-255. https://doi.org/10.1111/ele.13175

Cook-Patton SC, Leavitt SM, Gibbs D, et al (2020) Mapping carbon accumulation potential from global natural forest regrowth. Nature 585:545-550. https://doi.org/10.1038/s41586-020-2686-x

Cox PM, Betts RA, Jones CD, et al (2000) Acceleration of global warming due to carbon-cycle feedbacks in a coupled climate model. Nature 408:184-187. https://doi.org/10.1038/35041539

Dagon K, Sanderson BM, Fisher RA, Lawrence DM (2020) A machine learning approach to emulation and biophysical parameter estimation with the Community Land Model, version 5. Adv Stat Climatol Meteorol Oceanogr 6:223-244. https://doi.org/10.5194/ascmo-6-223-2020

Dai XQ, WANG HM, ZHANG LM (2020) An observation dataset of carbon and water fluxes of artificial coniferous forests in Qianyanzhou (2003-2010). Sci Data Bank 6:. https://doi.org/10.11922/csdata.2020.0036.zh

Domínguez MT, Aponte C, Pérez-Ramos IM, et al (2012) Relationships between leaf morphological traits, nutrient concentrations and isotopic signatures for Mediterranean woody plant species and communities. Plant Soil 357:407-424. https://doi.org/10.1007/s11104-012-1214-7

FAO (2020) Global Forest Resources Assessment 2020. FAO

Farquhar GD, von Caemmerer S, Berry JA (1980) A biochemical model of photosynthetic CO2 assimilation in leaves of C3 species. Planta 149:78-90. https://doi.org/10.1007/BF00386231

Fu YL, Yu GR, Sun XM, et al (2006) Depression of net ecosystem CO2 exchange in semi-arid Leymus chinensis steppe and alpine shrub. Agric For Meteorol 137:234-244. https://doi.org/10.1016/j.agrformet.2006.02.009

Gong H, Cui Q, Gao J (2020) Latitudinal, soil and climate effects on key leaf traits in northeastern China. Glob Ecol Conserv 22:e00904. https://doi.org/10.1016/j.gecco.2020.e00904

Harris NL, Gibbs DA, Baccini A, et al (2021) Global maps of twenty-first century forest carbon fluxes. Nat Clim Change 11:234-240. https://doi.org/10.1038/s41558-020-00976-6 
He, Ma, Pei, et al (2019) Effects of Predominant Tree Species Mixing on Lignin and Cellulose Degradation during Leaf Litter Decomposition in the Three Gorges Reservoir, China. Forests 10:360. https://doi.org/10.3390/f10040360

He P, Gleason SM, Wright IJ, et al (2020) Growing-season temperature and precipitation are independent drivers of global variation in xylem hydraulic conductivity. Glob Change Biol 26:1833-1841. https://doi.org/10.1111/gcb.14929

Heinrich VHA, Dalagnol R, Cassol HLG, et al (2021) Large carbon sink potential of secondary forests in the Brazilian Amazon to mitigate climate change. Nat Commun 12:1785. https://doi.org/10.1038/s41467-021-22050-1

Hidy D, Barcza Z, Haszpra L, et al (2012) Development of the Biome-BGC model for simulation of managed herbaceous ecosystems. Ecol Model 226:99-119. https://doi.org/10.1016/j.ecolmodel.2011.11.008

Hidy D, Barcza Z, Hollós R, et al (2021) User's Guide for Biome-BGCMuSo 6.1

Hidy D, Barcza Z, Marjanović H, et al (2016) Terrestrial ecosystem process model Biome-BGCMuSo v4.0: summary of improvements and new modeling possibilities. Geosci Model Dev 9:4405-4437. https://doi.org/10.5194/gmd-9-4405-2016

Hosman CA, Hansen BB, Holland PW (2010) The sensitivity of linear regression coefficients' confidence limits to the omission of a confounder. Ann Appl Stat 4:849-870. https://doi.org/10.1214/09AOAS315

Hu X, Liu C, Zheng X, et al (2019) Annual dynamics of soil gross nitrogen turnover and nitrous oxide emissions in an alpine shrub meadow. Soil Biol Biochem 138:1-9. https://doi.org/10.1016/j.soilbio.2019.107576

Knapp AK, Carroll CJW, Fahey TJ (2014) Patterns and Controls of Terrestrial Primary Production in a Changing World. In: Monson RK (ed) Ecology and the Environment. Springer, New York, NY, pp 205-246

Li H, Zhang F, Li Y, et al (2016) Seasonal and inter-annual variations in CO2 fluxes over 10 years in an alpine shrubland on the Qinghai-Tibetan Plateau, China. Agric For Meteorol 228-229:95-103. https://doi.org/10.1016/j.agrformet.2016.06.020

Li H, Zhu J, Zhang F, et al (2019) Growth stage-dependant variability in water vapor and CO2 exchanges over a humid alpine shrubland on the northeastern Qinghai-Tibetan Plateau. Agric For Meteorol 268:55-62. https://doi.org/10.1016/j.agrformet.2019.01.013

Li S, Zhang L, Ma R, et al (2020) Improved ET assimilation through incorporating SMAP soil moisture observations using a coupled process model: A study of U.S. arid and semiarid regions. J Hydrol 590:125402. https://doi.org/10.1016/j.jhydrol.2020.125402

Li X, Liu Q, Cai Z, Ma Z (2007) Specific leaf area and leaf area index of coniffr plantions in Qianyanzhou station of subtropical China. Chin J Plant Ecol 31:93-101. https://doi.org/10.17521/cjpe.2007.0012

Li YL, Yan JH, Meng Z, Huang JQ (2021) An observation dataset of carbon and water fluxes in a mixed coniferous broad-leaved forest at Dinghushan, Southern China (2003 - 2010). Sci Data Bank 6:. https://doi.org/10.11922/csdata.2020.0046.zh

Liu H, Chen W, Sudjianto A (2005) Relative Entropy Based Method for Probabilistic Sensitivity Analysis in Engineering Design. J Mech Des 128:326-336. https://doi.org/10.1115/1.2159025 
Ma H, Ma C, Li X, et al (2020) Sensitivity and Uncertainty Analyses of Flux-based Ecosystem Model

towards Improvement of Forest GPP Simulation. Sustainability 12:2584. https://doi.org/10.3390/su12072584

Miyauchi T, Machimura T, Saito M (2019) Estimating carbon fixation of plant organs for afforestation monitoring using a process-based ecosystem model and ecophysiological parameter optimization. Ecol Evol 9:8025-8041. https://doi.org/10.1002/ece3.5328

Neumann M, Godbold DL, Hirano Y, Finér L (2020) Improving models of fine root carbon stocks and fluxes in European forests. J Ecol 108:496-514. https://doi.org/10.1111/1365-2745.13328

Nguyen AT, Reiter S (2015) A performance comparison of sensitivity analysis methods for building energy models. Build Simul 8:651-664. https://doi.org/10.1007/s12273-015-0245-4

Norton J (2015) An introduction to sensitivity assessment of simulation models. Environ Model Softw 69:166-174. https://doi.org/10.1016/j.envsoft.2015.03.020

Pan S, Tian H, Dangal S, et al (2014) Modeling and Monitoring Terrestrial Primary Production in a Changing Global Environment: Toward a Multiscale Synthesis of Observation and Simulation. Adv Meteorol 2014:1-17. https://doi.org/10.1155/2014/965936

Pianosi F, Beven K, Freer J, et al (2016) Sensitivity analysis of environmental models: A systematic review with practical workflow. Environ Model Softw 79:214-232. https://doi.org/10.1016/j.envsoft.2016.02.008

Raj R, Hamm NAS, van der Tol C, Stein A (2014) Variance-based sensitivity analysis of BIOME-BGC for gross and net primary production. Ecol Model 292:26-36. https://doi.org/10.1016/j.ecolmodel.2014.08.012

Richard AA, Christopher FP (2020) Sensitivity Analysis of an OLS Multiple Regression Inference with Respect to Possible Linear Endogeneity in the Explanatory Variables, for Both Modest and for Extremely Large Samples. Econometrics 8:1-24. https://doi.org/10.3390/econometrics8010011

Ryan MG (1991) Effects of Climate Change on Plant Respiration. Ecol Appl 1:157-167. https://doi.org/10.2307/1941808

Seidl R, Thom D, Kautz M, et al (2017) Forest disturbances under climate change. Nat Clim Change 7:395-402. https://doi.org/10.1038/nclimate3303

Shields C, Tague C (2015) Ecohydrology in semiarid urban ecosystems: Modeling the relationship between connected impervious area and ecosystem productivity. Water Resour Res 51:302-319. https://doi.org/10.1002/2014WR016108

Stitt M, Schulze D (1994) Does Rubisco control the rate of photosynthesis and plant growth? An exercise in molecular ecophysiology. Plant Cell Environ 17:465-487. https://doi.org/10.1111/j.13653040.1994.tb00144.X

Sun L, Xia Z, Sang C, et al (2019) Soil resource status affects the responses of nitrogen processes to changes in temperature and moisture. Biol Fertil Soils 55:629-641. https://doi.org/10.1007/s00374-019-01379-2

Sun Q, Li B, Zhang T, et al (2017) An improved Biome-BGC model for estimating net primary productivity of alpine meadow on the Qinghai-Tibet Plateau. Ecol Model 350:55-68. https://doi.org/10.1016/j.ecolmodel.2017.01.025

Tatarinov FA, Cienciala E (2006) Application of BIOME-BGC model to managed forests. For Ecol Manag 237:267-279. https://doi.org/10.1016/j.foreco.2006.09.085 
Thornton PE, Law BE, Gholz HL, et al (2002) Modeling and measuring the effects of disturbance history and climate on carbon and water budgets in evergreen needleleaf forests. Agric For Meteorol 113:185-222. https://doi.org/10.1016/S0168-1923(02)00108-9

Thornton PE, Rosenbloom NA (2005) Ecosystem model spin-up: Estimating steady state conditions in a coupled terrestrial carbon and nitrogen cycle model. Ecol Model 189:25-48. https://doi.org/10.1016/j.ecolmodel.2005.04.008

Toriyama J, Hashimoto S, Osone Y, et al (2021) Estimating spatial variation in the effects of climate change on the net primary production of Japanese cedar plantations based on modeled carbon dynamics. PLOS ONE 16:e0247165. https://doi.org/10.1371/journal.pone.0247165

Turner DP, Ritts WD, Cohen WB, et al (2005) Site-level evaluation of satellite-based global terrestrial gross primary production and net primary production monitoring. Glob Change Biol 11:666-684. https://doi.org/10.1111/j.1365-2486.2005.00936.x

Vazquez-Cruz MA, Guzman-Cruz R, Lopez-Cruz IL, et al (2014) Global sensitivity analysis by means of EFAST and Sobol' methods and calibration of reduced state-variable TOMGRO model using genetic algorithms. Comput Electron Agric 100:1-12. https://doi.org/10.1016/j.compag.2013.10.006

Wang D, Ricciuto D, Post W, Berry MW (2011) Terrestrial Ecosystem Carbon Modeling. In: Padua D (ed) Encyclopedia of Parallel Computing. Springer US, Boston, MA, pp 2034-2039

Wang J, Feng L, Palmer PI, et al (2020) Large Chinese land carbon sink estimated from atmospheric carbon dioxide data. Nature 586:720-723. https://doi.org/10.1038/s41586-020-2849-9

White MA, Thornton PE, Running SW, Nemani RR (2000) Parameterization and Sensitivity Analysis of the BIOME-BGC Terrestrial Ecosystem Model: Net Primary Production Controls. Earth Interact $4: 1-85$

Woodrow IE, Berry JA (1988) Enzymatic Regulation of Photosynthetic CO2, Fixation in C3 Plants. Annu Rev Plant Physiol Plant Mol Biol 39:533-594. https://doi.org/10.1146/annurev.pp.39.060188.002533

Wright IJ, Dong N, Maire V, et al (2017) Global climatic drivers of leaf size. Science 357:917-921. https://doi.org/10.1126/science.aal4760

Wu JB, Guan DX, Wang AZ (2020) A dataset of carbon and water flux observation in a broad-leaved red pine forest in Changbai Mountain (2003-2010). Sci Data Bank 6: https://doi.org/10.11922/csdata.2020.0041.zh

Yan M, Tian X, Li Z, et al (2016) A long-term simulation of forest carbon fluxes over the Qilian Mountains. Int J Appl Earth Obs Geoinformation 52:515-526. https://doi.org/10.1016/j.jag.2016.07.009

Yu GR, Ren W, Chen Z, et al (2016) Construction and progress of Chinese terrestrial ecosystem carbon, nitrogen and water fluxes coordinated observation. J Geogr Sci 26:803-826. https://doi.org/10.1007/s11442-016-1300-5

Yu GR, Wen XF, Sun XM, et al (2006) Overview of ChinaFLUX and evaluation of its eddy covariance measurement. Agric For Meteorol 137:125-137. https://doi.org/10.1016/j.agrformet.2006.02.011

Yu GR, Zhang LM, Sun XM, et al (2008) Environmental controls over carbon exchange of three forest ecosystems in eastern China: CARBON EXCHANGE OF THREE FOREST ECOSYSTEMS IN EASTERN CHINA. Glob Change Biol 14:2555-2571. https://doi.org/10.1111/j.13652486.2008.01663.x 
651 Zaehle S, Sitch S, Smith B, Hatterman F (2005) Effects of parameter uncertainties on the modeling of terrestrial biosphere dynamics.

Glob

Biogeochem

Cycles

19:. https://doi.org/10.1029/2004GB002395

Zagayevskiy Y, Deutsch CV (2015) A Methodology for Sensitivity Analysis Based on Regression: Applications to Handle Uncertainty in Natural Resources Characterization. Nat Resour Res 24:239-274. https://doi.org/10.1007/s11053-014-9241-0

Zhang FW, Li HQ, Zhao L, Zhang LM (2020) An observation dataset of carbon, water and heat fluxes over an alpine shrubland in Haibei (2003-2010). Sci Data Bank 6:. https://doi.org/10.11922/csdata.2020.0034.zh

660 Zhang H, Deng Q, Hui D, et al (2019) Recovery in soil carbon stock but reduction in carbon stabilization after 56-year forest restoration in degraded tropical lands. For Ecol Manag 441:1-8. https://doi.org/10.1016/j.foreco.2019.03.037

Zhou J, Xia J, Wei N, et al (2021) A traceability analysis system for model evaluation on land carbon dynamics: design and applications. Ecol Process 10:12. https://doi.org/10.1186/s13717-021- 


\section{Supplementary Files}

This is a list of supplementary files associated with this preprint. Click to download.

- Supplementary.pdf 